INTERNATIONAL MONETARY FUND

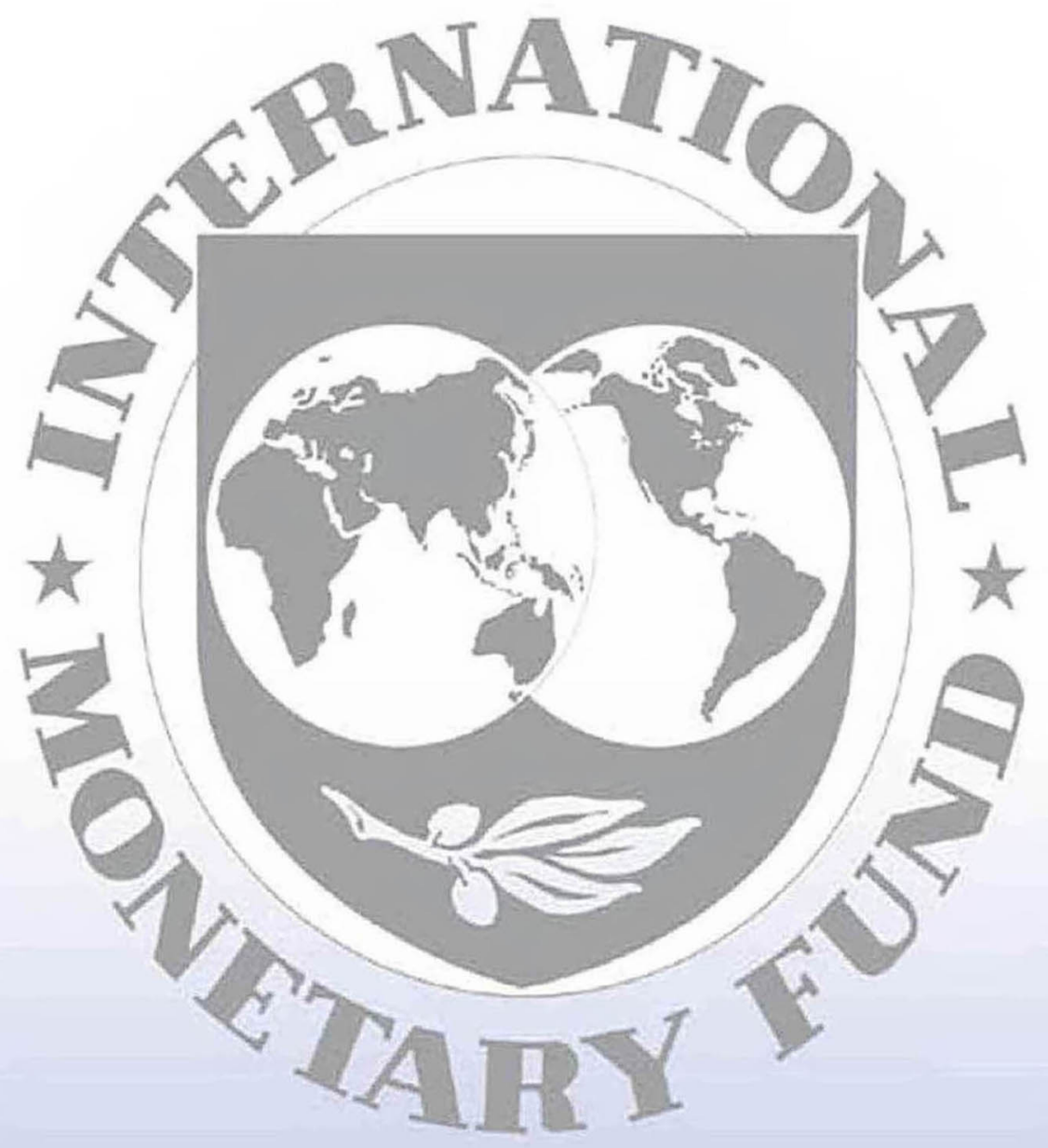

Staff

Country

Reports 


\section{Turkey: Selected Issues}

This paper on Turkey was prepared by a staff team of the International Monetary Fund as background documentation for the periodic consultation with the member country. It is based on the information available at the time it was completed on October 31,2012. The views expressed in this document are those of the staff team and do not necessarily reflect the views of the government of Turkey or the Executive Board of the IMF.

The policy of publication of staff reports and other documents by the IMF allows for the deletion of market-sensitive information.

Copies of this report are available to the public from

International Monetary Fund • Publication Services

$70019^{\text {th }}$ Street, N.W. • Washington, D.C. 20431

Telephone: (202) 623-7430 • Telefax: (202) 623-7201

E-mail: publications@imf.org Internet: http://www.imf.org

\section{International Monetary Fund Washington, D.C.}




\section{INTERNATIONAL MONETARY FUND}

\section{TURKEY}

\section{Selected Issues}

Prepared by Heiko Hesse, Yanliang Miao, Jacques Miniane, Robert Tchaidze

Approved by European Department

October 31, 2012

I. Turkey's New Monetary Framework

A. Introduction

B. The New Framework.

C. Evaluating the New Framework

D. Was There an Alternative?

E. Conclusions

Figures

CBRT's New Framework

II. Turkey's Current Account Rebalancing: Cyclical or Structural?

Figure

1. Turkey's Current Account Deficit and Its Determinants ...

Table

1. Turkey Current Account Adjustment Dynamics

III. Macroprudential Framework and Policies in Turkey ……….......................................... 26
A. Background
B. MPP Framework and Literature. .27
C. Turkey's MPP Measures and Framework
D. Expanding the Tool Kit.
E. Conclusion

Figure

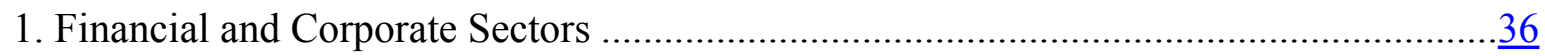

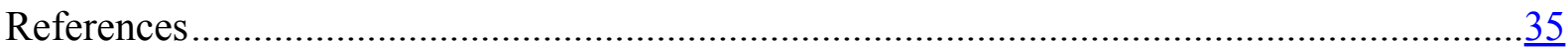

Annexes

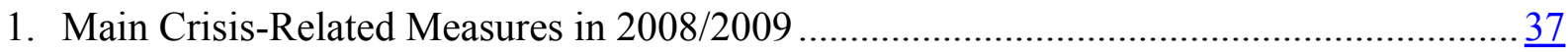

2. Recent Macroprudential Measures............................................................................ 


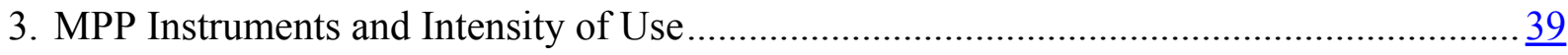

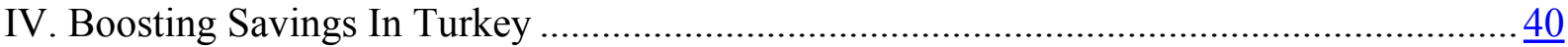



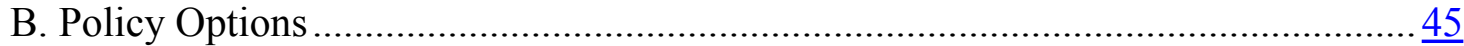

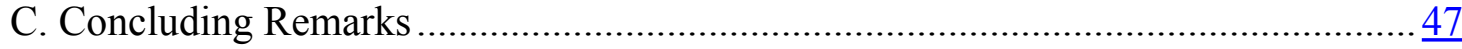

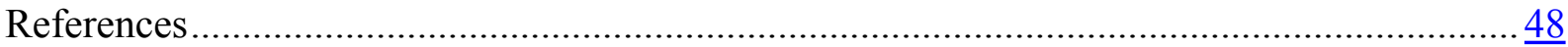




\section{TURKEY'S NeW MONETARY FRAMEWORK ${ }^{1}$}

Since late 2010, the Central Bank of Republic of Turkey (CBRT) has been implementing the monetary policy in a manner that commentators and analysts have referred to as unorthodox or experimental. Instead of relying on one interest rate as inflation-targeting central banks usually do-raising it as inflation pressures intensify and lowering it as they abate - the CBRT, in face of strong capital inflows attracted by high nominal interest rates, resorted to utilizing a wide variety of instruments. The CBRT's rationale is that achieving two objectives-price and financial stability - requires more than just an interest rate-based mechanism.

This note describes and assesses success of the new framework. While it is difficult to conduct proper empirical analysis, given a rather short time period under consideration, a preliminary view can be formed. The first version of the framework, in place until October 2011, does not seem to have achieved a timely or significant reduction in external and internal imbalances. The second version of the framework, currently in place, has witnessed an unwinding of imbalances, but causal links are not obvious and complexity of the framework may have introduced costly distortions.

\section{A. Introduction}

1. In the aftermath of the 2008-09 global financial crisis the Turkish authorities faced a challenging environment. From late 2010, strong capital inflows led the Turkish lira (TL) to appreciate, undermining competitiveness, fueling a credit boom, adding to inflationary pressures, and increasing imports. These developments left the economy exposed to the risk of a sudden capital flow reversal. Were the inflows to dry up - either in response to the Turkey's imbalances or because of changes in the global risk appetite - the lira would have rapidly depreciated, adding to inflationary pressures (this time through the exchange-rate pass-through), affecting balance sheets of banks and corporates that had been borrowing in FX, and undermining overall confidence. Indeed, earlier examples of such reversals led to sharp contractions of output. ${ }^{2}$

2. The CBRT, operating as an inflation-targeting central bank since 2006, became increasingly vocal about financial stability ${ }^{3}$ in mid-2010. It pointed to rapid expansion of

\footnotetext{
${ }^{1}$ Prepared by Robert Tchaidze (EUR).

${ }^{2}$ In 2001 seasonally-adjusted GDP fell by 11 percent from peak to trough and in 2009 by 13 percent.

${ }^{3}$ Article 4, part I of the Law on the Central Bank of The Republic of Turkey states that "The fundamental duties of the Bank shall be ... to take precautions for enhancing the stability in the financial system and to take regulatory measures with respect to money and foreign exchange markets."
} 
domestic credit and an increase in external borrowing by corporates and banks, with a significant share of it happening on a short-term basis. Together with real appreciation of the Turkish lira - significantly above what the CBRT considered to be consistent with the fundamentals and driven both by inflation differentials and nominal strengthening of the currency - this initiated a sharp widening of the current account deficit.
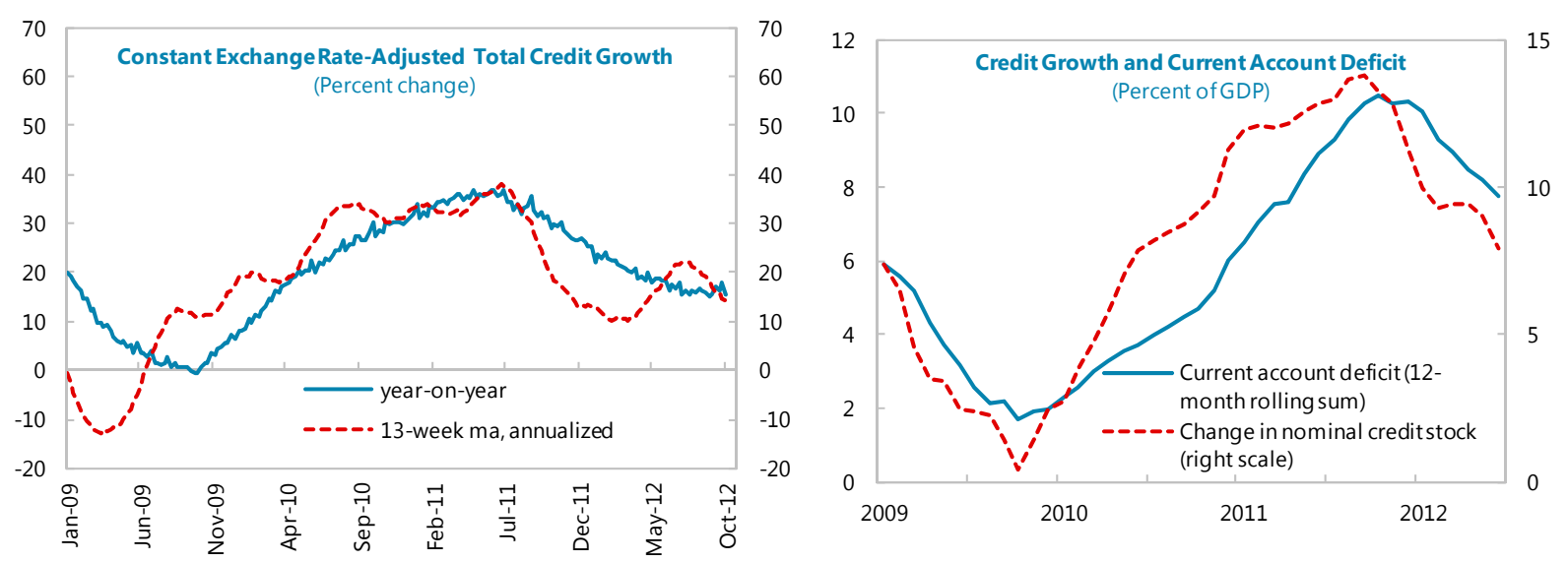

Sources: Central Bank of Turkey.

3. Reliance on a simple, interest-rate guided, framework to fight inflation proved in the CBRT's view to be counter-productive: interest rates, hiked to combat demand-induced inflation, were attracting inflows and inducing inflationary pressures instead of suppressing them. Thus, the new framework was adopted with a view to deter excessive short-term capital inflows, while changing their composition from short-term to long-term and from debt to equity, and insulating domestic demand from excessive swings.

4. Although it is difficult to assess success of this framework given a short time-span of its implementation, this note allows forming a preliminary view by answering two sets of questions:

- How successful has the CBRT's new framework been from the point of view of inflation targeting? That is, do market participants perceive it as such? How has the new framework affected inflation expectations? Has the CBRT's ability to affect market rates changed? Have the overall monetary conditions been as tight as needed?

- In addition, has the framework helped the CBRT achieve its declared goals of reducing the current account deficit and reshaping the capital flows?

\section{B. The New Framework}

\section{Instruments}

5. The set of instruments the CBRT has been relying on includes: 
(i) The interest rate corridor, delineated by overnight borrowing and lending rates, within which the CBRT varies price of liquidity it provides.

(ii) A set of repo facilities, through which liquidity is injected.

- The main ones are quantity and price auctions available to open market operations participants. Currently, the quantity auctions are held on days deemed "ordinary," and the price auctions on days deemed "extraordinary." There is also a facility for primary dealer banks, in which liquidity is provided through a quantity auction, and a possibility for the CBRT to inject liquidity via a price auction, executed after regular daily auctions.

- For the price auctions maturities are 1-week, 1-month and 3-month, while for the quantity auctions maturity is 1 -week. The interest rate for the latter is set by the CBRT and, since May 2010, serves as the policy rate.

(iii) Reserve requirement (RR) ratios, which are differentiated by currency and, since January 2011, by maturity.

(iv) Since September 2011, the CBRT allows for a share of the RR on TL-denominated liabilities to be held in FX and gold. Currently, this share is 60 percent for FX and 30 percent for gold and varying multipliers, Reserve Option Coefficients (ROC), apply. ${ }^{4}$

(v) Finally, regular and irregular FX auctions, buying or selling. In rare circumstances, the CBRT resorts to direct interventions into the FX market.

6. The CBRT also guides markets' expectations by announcing certain limits on liquidity flow and stock of liquidity that can be injected via different facilities.

\section{Defining the CBRT effective rate}

7. Although the CBRT has an official policy rate, the recent modifications to the framework have effectively reduced its relevance. That and a short period of its existencesince May 2010 - make it necessary to establish a more consistent measure of the monetary policy, with a longer history, which herein is referred to as "the effective rate."

\footnotetext{
${ }^{4}$ For FX, ROCs are 1.4 for $0-40$ percent; 1.7, 2.0, 2.2, and 2.3 for increments of 5 percentage points until 60 percent. For gold, ROCs are 1 for $0-20$ percent, 1.5 for 20-25 percent, and 2.0 for 25-30 percent.
} 
8. The effective rate is defined as the weighted average of the interest rates at which the CBRT injects liquidity through its various facilities on any given day; and as the overnight borrowing rate otherwise. ${ }^{5}$ This series needs to be introduced because:

(i) Until 2008, the banking system had excess liquidity and the CBRT was withdrawing it;

(ii) Since 2008 and until May of 2010 the CBRT used only price auctions to inject liquidity;

(iii) In May 2010 the CBRT introduced the policy rate, at which it began to provide liquidity via quantity auctions;

(iv) Finally, since December 2011, the CBRT injects liquidity via both types of auctions.


Sources: CBRT and IMF staff calculations.

9. Thus, in 2006-08 the effective rate is most of the time equal to the overnight borrowing rate; afterwards, whenever quantity auctions are the only liquidity-providing facility used, the effective rate matches the policy rate; and, finally, whenever a price auction takes place - whether by itself or alongside a quantity auction - the effective rate tends to rise above the policy rate as price auctions usually take place in the environment of increased demand for liquidity.

\footnotetext{
${ }^{5}$ The calculations are done on a daily basis, using compound rates.
} 


\section{Different versions of the framework}

10. Comparing the effective rate with the overnight interbank rate shows that the new framework has, in fact, been implemented in two rather distinct ways during two episodes: firstly, from October 2010 until approximately October 2011 and secondly, from October 2011 onwards. $^{6}$ The former is the period that started with strong capital inflows and associated difficulties that forced the CBRT to adopt the new framework. The second episode started when inflows weakened and the CBRT faced difficulties stabilizing the exchange rate, prompting it to adjust the framework.

11. At first, the CBRT's view was that of the overvalued exchange rate, and the new framework was supposed to bring about a correction via nominal depreciation. The CBRT $\operatorname{argued}^{7}$ that high nominal interest rates attracted capital inflows feeding into credit boom and that meanwhile elasticity of demand for credit to interest rates was too low to have any meaningful impact. Instead it had to rely on the RR ratios to combat excessive credit growth. Thus, during the first episode, the CBRT proceeded as follows:

- It lowered the overnight borrowing rate, "opening down" the interest rate corridor and a few times adjusted downwards the policy rate;

- It tightened the RR ratios and started to differentiate them by maturity, penalizing short-term liabilities; ${ }^{8}$

- $\quad$ By varying the amount of liquidity it was providing via the quantity repo auctions, it generated a lot of volatility in the interbank rates;

- $\quad$ Finally, the CBRT continued purchasing FX via regular daily auctions, thus injecting more lira liquidity. The pre-announced amounts were changing in line with perceived strength of capital inflows, increasing as the inflows strengthened and decreasing as they weakened.

12. The policy-induced uncertainty in the short-term market rates was a cornerstone of this strategy and the "interest rate corridor"-formed by the CBRT's overnight borrowing and lending rates - came to serve as a signaling device. When the CBRT introduced the

\footnotetext{
${ }^{6}$ For simplicity, October 17, 2011 is taken as the starting point of the second episode, although in reality there was a transition period of about three months.

${ }^{7}$ See, for instance, http://www.tcmb.gov.tr/yeni/iletisimgm/Basci_Tek_Eng.pdf

${ }^{8}$ By June 2011, the RRs on short-term TL liabilities were increased to 16 percent from 5 percent in October 2010.
} 
policy rate, the overnight interbank rates used to be kept close to it, and thus, it was indicating what a short-term investor was likely to earn. As the interest rate corridor was "opened down," the volatility of the market rates was allowed to increase proportionally with it, even if on average they continued to remain close to the policy rate. Thus, now it

was the floor of the corridor that came to indicate a guaranteed rate of return. This, it was hoped, would deter speculative inflows and reverse appreciation of the lira.


Sources: CBRT; and IMF staff calculations.

13. However, altogether these operations led to a significant increase in liquidity provision, which supported credit growth, and thus, turned to be counterproductive in containing the current account deficit or combating inflationary pressures. Eventually, expansion of liquidity led to rapid nominal depreciation, which intensified inflationary pressures and undermined confidence in lira.

14. In August of 2011, when global risk appetitive worsened and capital flows reversed, the CBRT stopped purchasing FX and switched to selling it. It also reduced the volumes of quantity auctions, eventually "opened up" the interest rate corridor, and introduced price auctions (the first one took place on December 29, 2011), which led to an increase in the effective rate. Meanwhile, the RR ratios were lowered and the CBRT left them unchanged from November (for TL) and December (for FX) of 2011 on. The CBRT also stopped its regular FX auctions - be it for purchase or sale - after, in addition to selling \$12.7 billion via auctions, it had to intervene two times in 2011 and three times in early January 2012, selling an additional total of $\$ 3.4$ billion. 
15. Since January 5, 2012, the CBRT framework has been as follows: no direct FX operations; no changes in the RR ratios, but provision of incentives for the banks to hold their RRs on TL liabilities in FX and gold; ${ }^{9}$ and finally, varying daily the amount of liquidity provided via different facilities - one-week quantity and price auctions, and one-month price auctions - thus, varying daily the effective cost of funding.

16. This version of the framework gave the CBRT an ability to switch between tight and loose interest-rate environment on a daily basis, a flexibility it felt it needed given the uncertainties surrounding both the global and domestic real and financial conditions that the CBRT has been facing since the late 2011. Consequently, given the daily volatility in the cost of the CBRT liquidity, commercial banks started to incorporate the top of the interest rate corridor into their pricing decisions.

17. These operations led to two periods of tightened liquidity — at the end of 2011 and in April-July of 2012. Since then, the CBRT has lowered effective rates in what it seems to be an attempt to stimulate the economy.

Additionally, in September it decreased the overnight lending rate by 150 basis points to send an additional signal that the effective

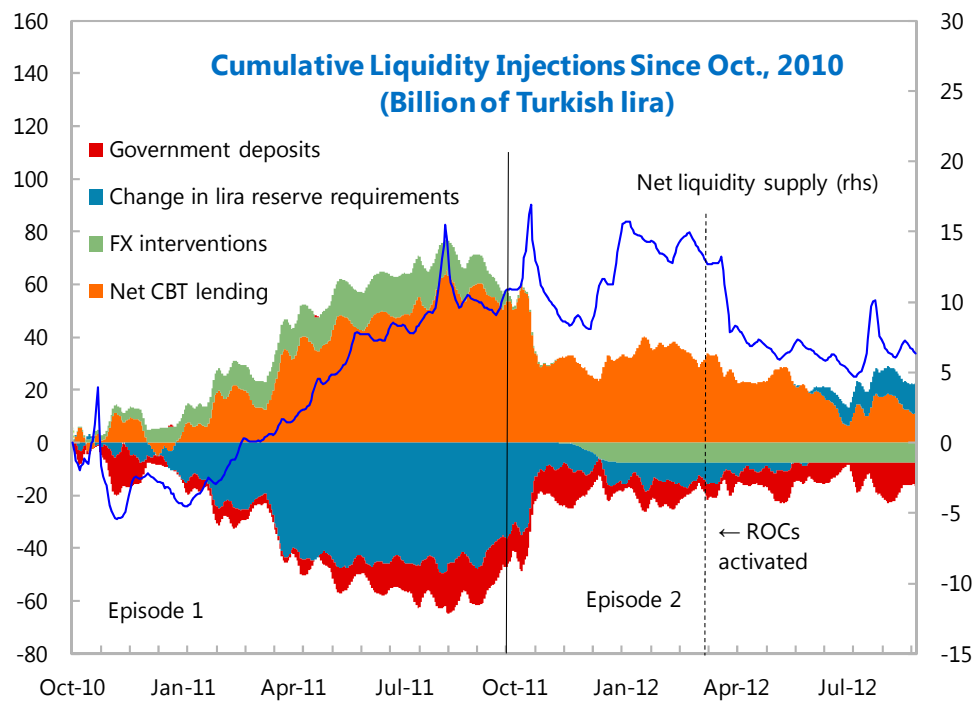
rates are going to remain relatively low.

\section{Evaluating the New Framework}

\section{Market participants' and analysts' views about the framework}

18. A frequent critique of the new framework is that it makes it difficult to judge objectives and priorities of the CBRT. ${ }^{10}$ Even though it formally remains an inflation-targeting central bank, many analysts put forward an alternative interpretation, especially when analyzing its strategy in 2012. This interpretation is that the CBRT loosens

\footnotetext{
${ }^{9}$ This allows for the CBRT's gross FX reserves to increase, even if the net reserves stay unchanged. As of August 17, 2012 at least 50 percent of these "converted" RRs should be held in the US dollars.

${ }^{10}$ A number of announcements, coming from the CBRT under the new framework, has roughly doubled, also making interpretation of its actions difficult.
} 
monetary stance as long as the capital inflows allow for the stable exchange rate. However, whenever the exchange rate comes under pressure, the CBRT tightens to prevent excessive depreciation of the currency, which would feed into inflation and may hurt balance sheets of the corporate that have a significant open FX position. ${ }^{11}$

19. Indeed, distribution of the effective rates shows that, in spite of elevated inflation, most of the time they are kept around 6 percent. The rates are sometimes hiked, but these periods tend to be short-lived (see below) and the hikes tend to be clustered, suggesting that the CBRT tries to lower the rates but is at times forced to reverse its actions. One also observes an increase in correlation between the lira-dollar exchange and the effective rate since late 2011.
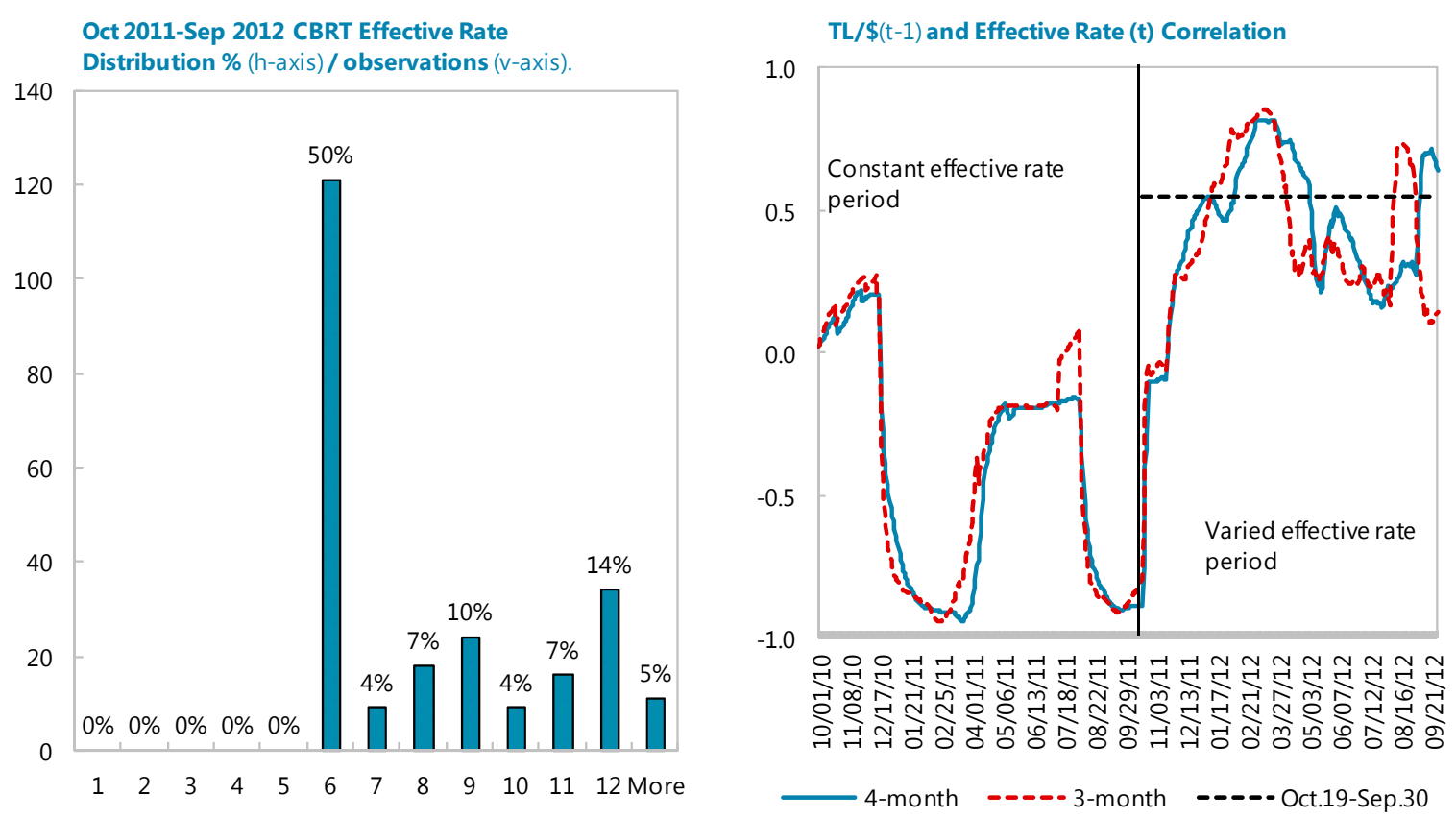

Source: CBRT and IMF staff calculations.

\footnotetext{
${ }^{11}$ These are quotes from the market commentaries that suggest such an interpretation: "[T]he impulse response function of OMO suggests that the CBT tightens liquidity conditions in response to a depreciation of the lira. The rise in the CBT's funding rate, in turn, supports the currency, with its maximum impact taking place within 10 days" (Citi); "[There is a] very close link between the monetary policy stance and availability of external financing. Unless the latter is sufficiently ample, monetary policy cannot ease much, no matter how desirable it may be, lest the lira weakens and complicates the inflation outlook and ruins corporate sector balance sheets" (Global Source Partners).
} 


\section{Inflationary expectations}

20. Given that the markets may have doubts in the CBRT's commitment to the inflation target, it would not be surprising for inflation expectations ${ }^{12}$ to reflect this. Indeed, as the charts below show, until the new framework, inflationary expectations were well approximated by an average of the target inflation and the latest available observation. However, this link broke down at the inception of the new framework and since then, expectations have been broadly flat, affected neither by the very low (in fact, the lowest in 40 years) inflation in April 2011, nor by the very high inflation a year later.

21. This suggests that participants of the surveys, having difficulties interpreting the CBRT's action, are "rationally inattentive" and report the numbers around the top part of the inflation target band. OECD's 2012 Economic Survey similarly finds a diminishing role of inflation targets and increasing role of a constant in explaining inflationary expectations.
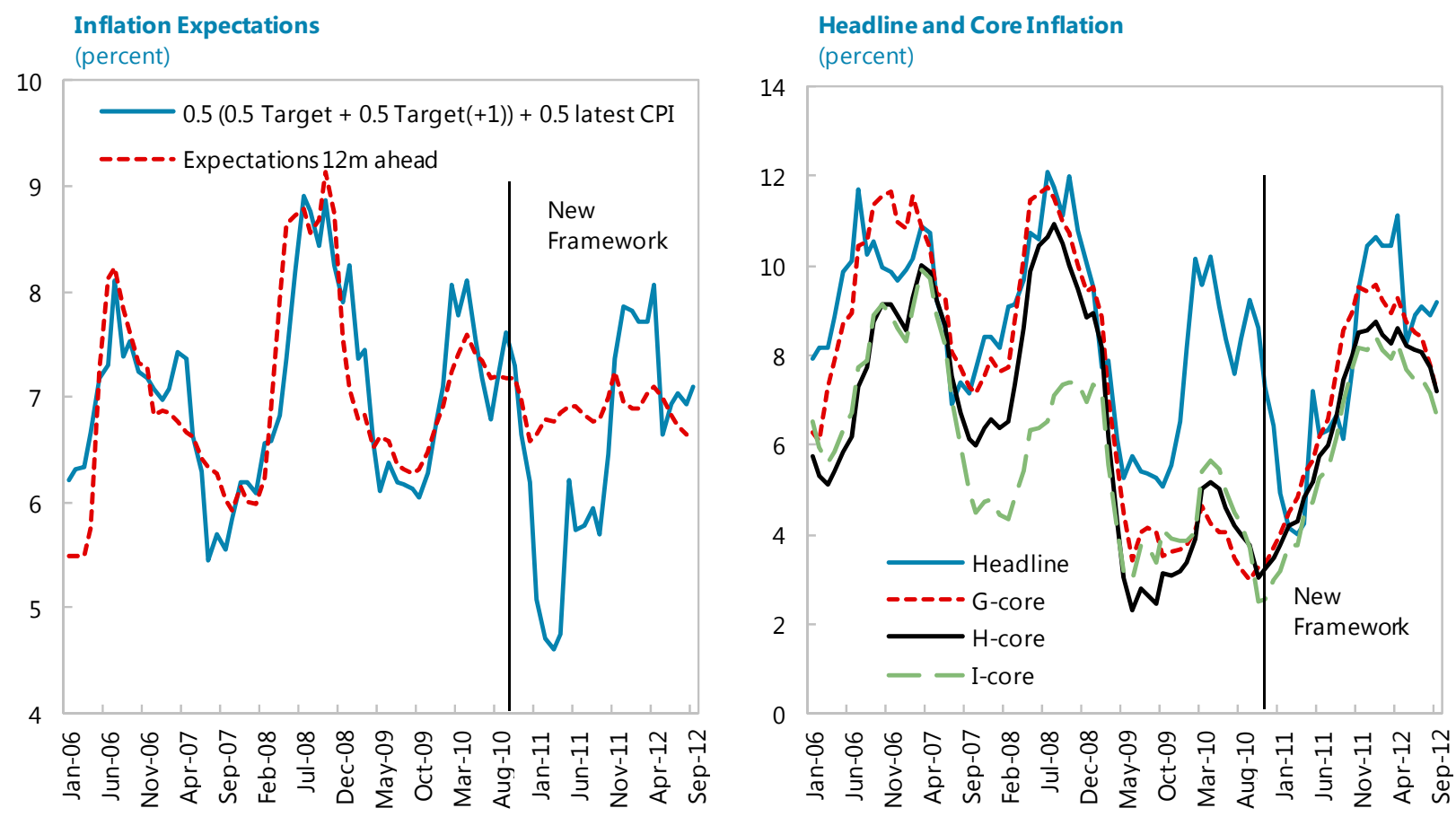

Sources: CBRT; and IMF staff calculations.

\footnotetext{
${ }^{12}$ The CBRT conducts surveys twice a month. In these surveys it asks participants about their expectations of inflation 12-months ahead. These surveys are conducted on the 15th and the last day of each month and thus, the participants can take into account the actual inflation realization for the previous month, which is released in the first week of each month. The numbers used in this note are averages of two monthly surveys.
} 
22. An alternative interpretation is that expectations have become well-anchored.

However, that would be reflected in behavior of the core-inflation measures as well. Instead, one observes that as the new framework was adopted, they bottomed out and started to steadily increase until peaking in spring 2012.

\section{Affecting market rates}

23. The operations of a central bank are effective as long as it can in time and to a needed extent affect market rates. Thus, it is important to examine if the link between the effective rate and the interbank rate has changed.

24. As illustrated in the charts earlier, until introduction of the new framework this link used to be very tight. This spread has intentionally become very volatile when the CBRT introduced the new framework, yet on average it remained close to zero. As the framework changed in late 2011, so did the behavior of the spread: on average it increased and so did its volatility and persistence.

\begin{tabular}{lcccccc}
\hline & Average & St. Dev. & $\begin{array}{c}\text { Auto- } \\
\text { correlation }\end{array}$ & Maximum & Minimum & Observations \\
\hline $\begin{array}{l}\text { Oct. 1, 2010- } \\
\text { Oct. 14, 2011 }\end{array}$ & 0.14 & 1.22 & 0.28 & 1.93 & -4.07 & 261 \\
$\begin{array}{l}\text { Oct. 17, 2011 } \\
\text {-Sep. 28, 2012 }\end{array}$ & 1.49 & 2.00 & 0.68 & 5.35 & -2.64 & 242 \\
\hline
\end{tabular}

25. Examining the behavior of the spreads suggests that the behavior of the spread is linked to the strength of capital inflows, which manifest itself in the level and volatility of the nominal exchange rate: when the exchange rate is stable, the spread declines; but with volatile or appreciated exchange rate and low effective rates, the spreads widen, suggesting that markets expect the exchange rate to depreciate and/or the effective rates to tighten.
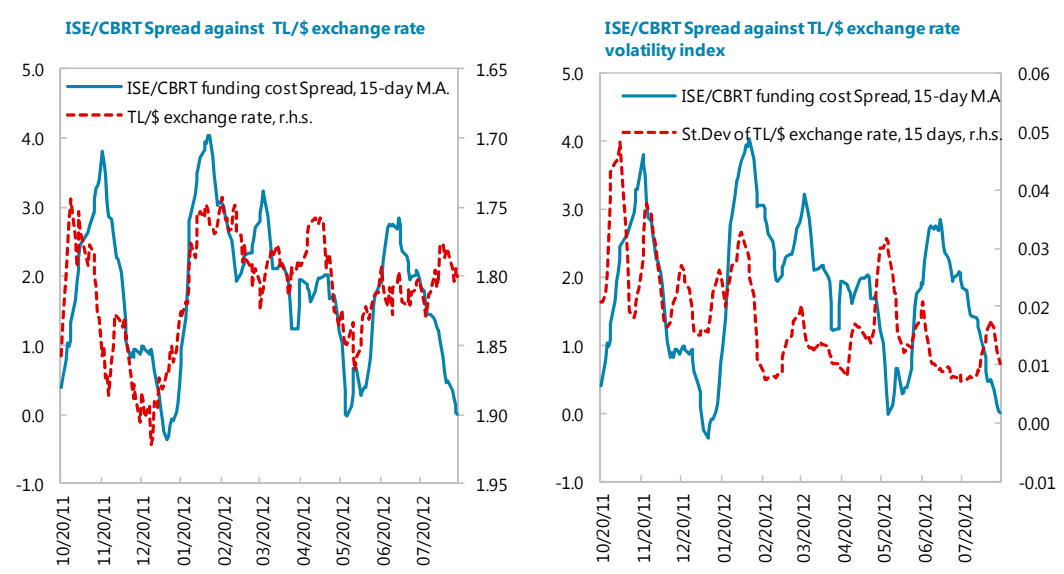

Sources: CBRT and IMF staff calculations. 
26. As argued earlier, in response to weak capital inflows, the CBRT tends to increase the effective rates, and in these circumstances, the spread declines again: with the effective rates high and the market rates bounded from above by the top of the interest rate corridor, the spread is being "squeezed from below."

\section{Has monetary policy been sufficiently tight?}

27. Whatever an operational framework may be, it should result in tightening or loosening of monetary conditions as required by the macroeconomic environment. To assess the appropriateness of the monetary policy stance of the CBRT, the Taylor-rule framework can be used.

28. Traditionally, Taylor rules are estimated as a reaction function, so that the responses to inflation and output gap can be evaluated. Alternatively, Taylor rules are used as benchmarks, against which the actual rates are judged. Both of these exercises are near impossible to do given frequent structural breaks in the way the monetary policy has been conducted and absence of consensus on what the appropriate coefficients should be for a Taylor rule in a country like Turkey. However, the most commonly known Taylor rulewith a response of 0.5 to both inflation and output gaps and real interest rate target of 2 percent, and corrected for Turkey's time-varying inflation target — can be used to form a view.

29. Comparing this Taylor rule with the actual rates shows that in 2006-08 the latter were, in fact, tighter than what the Taylor rule prescribes and yet, despite this "excess" tightening, both inflation and output gaps were persistently positive. This observation suggests that this particular specification of the Taylor rule is not "tight" enough for Turkey. Observing that in 2010-11 the actual rates were looser-on average by some 350 basis points - than what the Taylor rule suggests, allows to conclude that under the new framework, the monetary policy stance was too loose.

30. An important caveat is that even though the CBRT's effective rates were not tight enough, the interbank rates were less so, since, as discussed earlier, the operational framework introduced a non-zero spread between the two.

31. One should also note that the specification of the rule discussed herein is that of a closed economy, while in an open economy like Turkey's, a real exchange rate gap is an additional source of monetary tightening or loosening. Since, according to the staff estimates, the real exchange rate has been some 10-20 percent overvalued in 2010-11, the need for the interest rate tightening was probably not as high as the Taylor rule suggests. 


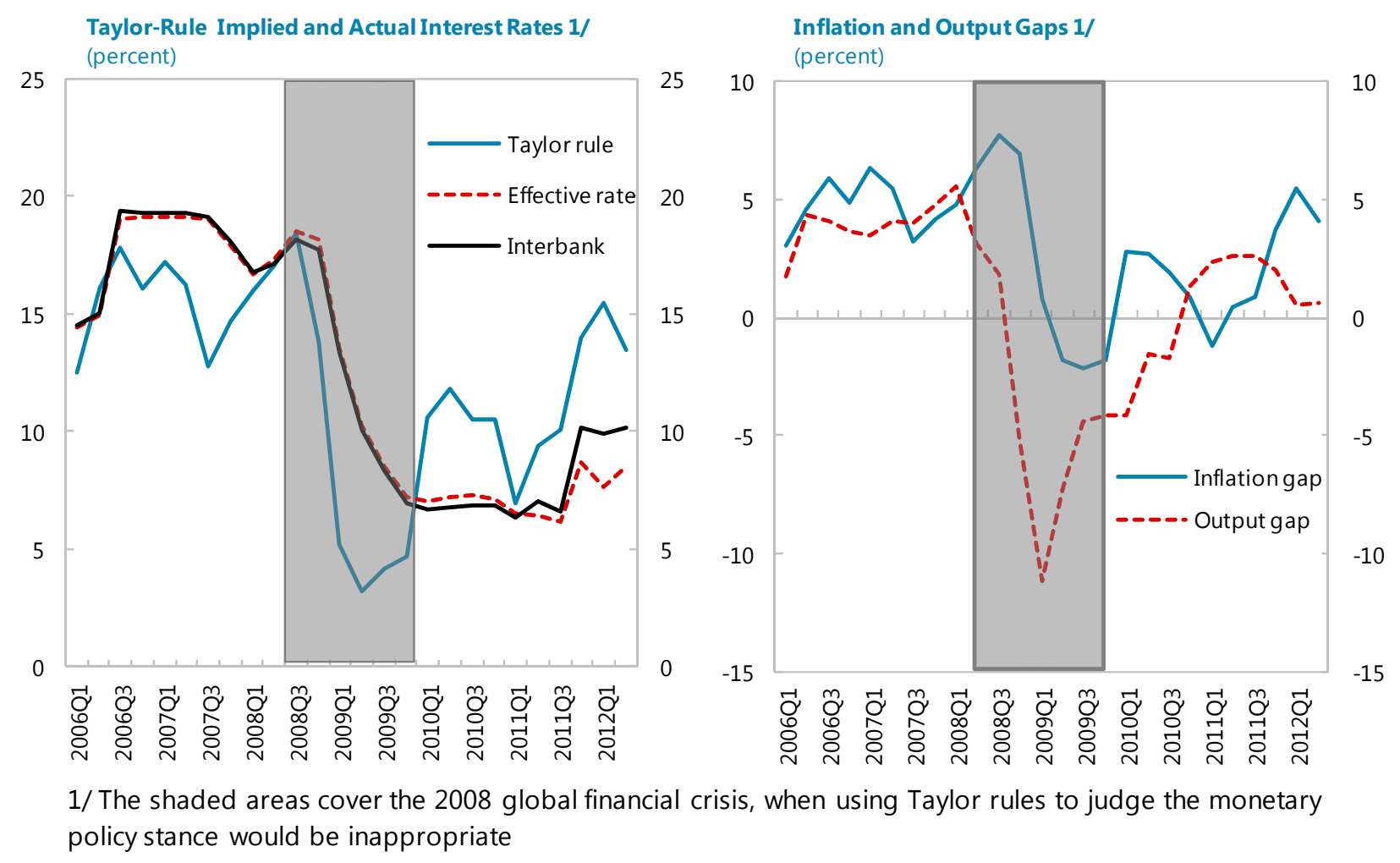

Sources: CBRT; and IMF staff calculations.

\section{What impact did CBRT policies have on external imbalances?}

32. In order to evaluate the impact of CBRT policies in reducing external imbalances one needs to examine the variables it has been trying to influence:

- $\quad$ The real exchange rate, which in late 2010 was seen as overvalued, and now is seen by the CBRT as in line with the fundamentals;

- $\quad$ CPI inflation, headline and core, which is the ultimate objective of the CBRT;

- $\quad$ Current account deficit and structure of its financing;

- $\quad$ The level of reserves, though not a direct objective of the CBRT but an important buffer in an economy exposed to volatile capital inflows.

33. Looking at these variables (Figure 2), one would arrive at a conclusion that in 2011, the framework did not deliver the desired outcomes: even though the currency depreciated in nominal terms and there were improvements the current account deficit and its financing on a monthly basis, in terms of the rolling12-month sums, the current account deficit continued to widen and inflows of debt in general and short-term debt in particular continued to increase as well. Meanwhile, inflation accelerated from the lowest in 40-years level (April of 2011) to the levels way above the CBRT's target, "eating up" a significant share of the real depreciation gains. An attempt to defend the currency succeeded in 
reversing the trend, but also led to a significant loss of reserves before needed tightening was put in place.

34. The framework adopted in 2012 still needs to be tested. The current account deficit reversed and the debt flows started to decrease while this version of the framework was in place. However, one should take into account that unwinding of external imbalances has been accompanied by a sharp deceleration of the domestic demand, which means that were domestic demand to bounce back, the correction of imbalances may revert. Among the factors that may have contributed to deceleration was the interest rate tightening itself, rather than the way in which the CBRT has delivered this tightening. Finally, in the last few months there was some reversal in improvements of the financing of the current account deficit.

\section{Was There an Alternative?}

35. The main motivating factor behind the CBRT's switch to the new framework was its perceived inability to deal with capital inflows. But was this perception well founded?

36. The charts below show that indeed in 2010-12 tightening of the interbank interest rates was associated with widening of the current account deficit, supporting the CBRT's desire to move away from the traditional framework. However, an analogous chart for 2006-08 demonstrates the opposite: tighter real rates led to smaller current account deficit.

Current Account and Real Interest Rates in 2006-8 (percent)

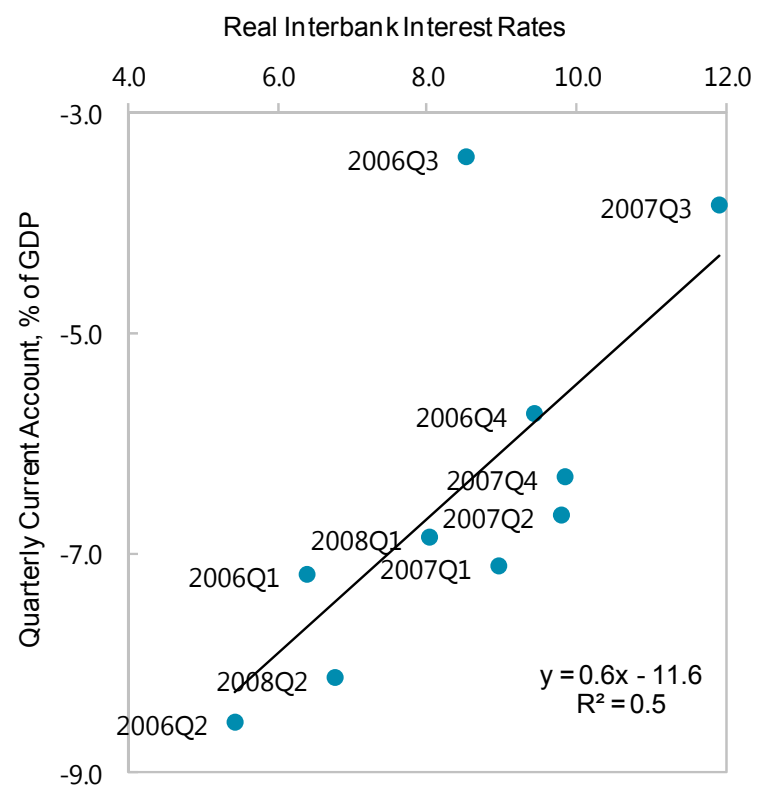

Current Account and Real Interest Rates in 2010-12 (percent)

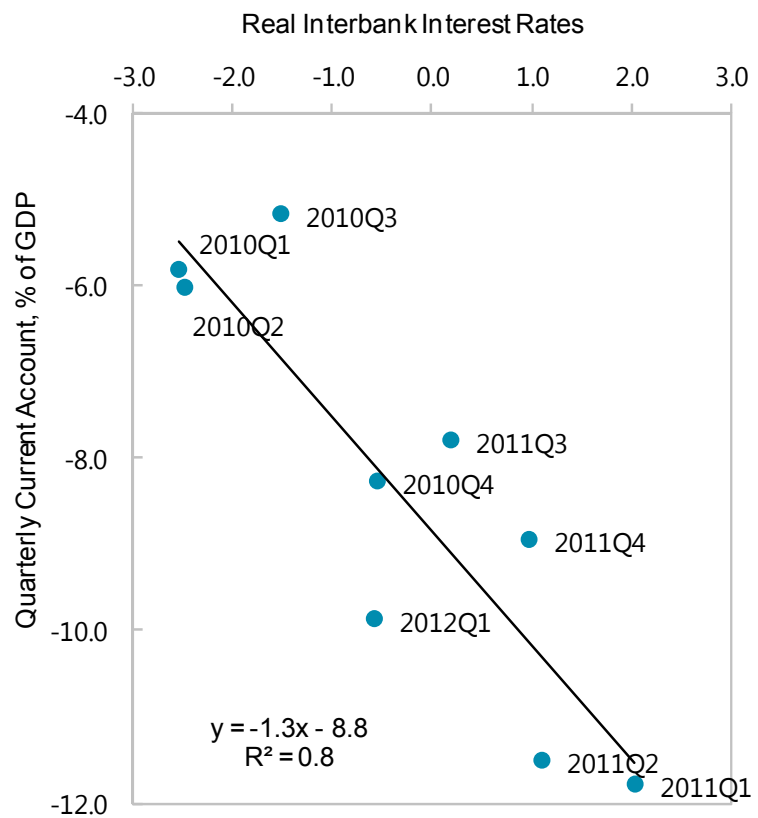

Sources: CBRT; and IMF staff calculations. 
37. What could have led to such a change? Could it be that the Turkish economy has become more attractive for carry-trade flows? While a lot of other factors (such as improved fundamentals, exchange rate expectations, etc) could be at play, from the point of view of an interest-rate differential only, Turkey was, in fact, much more attractive in 2006-8 than in 2010-11 as it can be seen, from a comparison of Turkish interbank rates with policy rates in advanced countries and money market rates in selected emerging economies. ${ }^{13}$
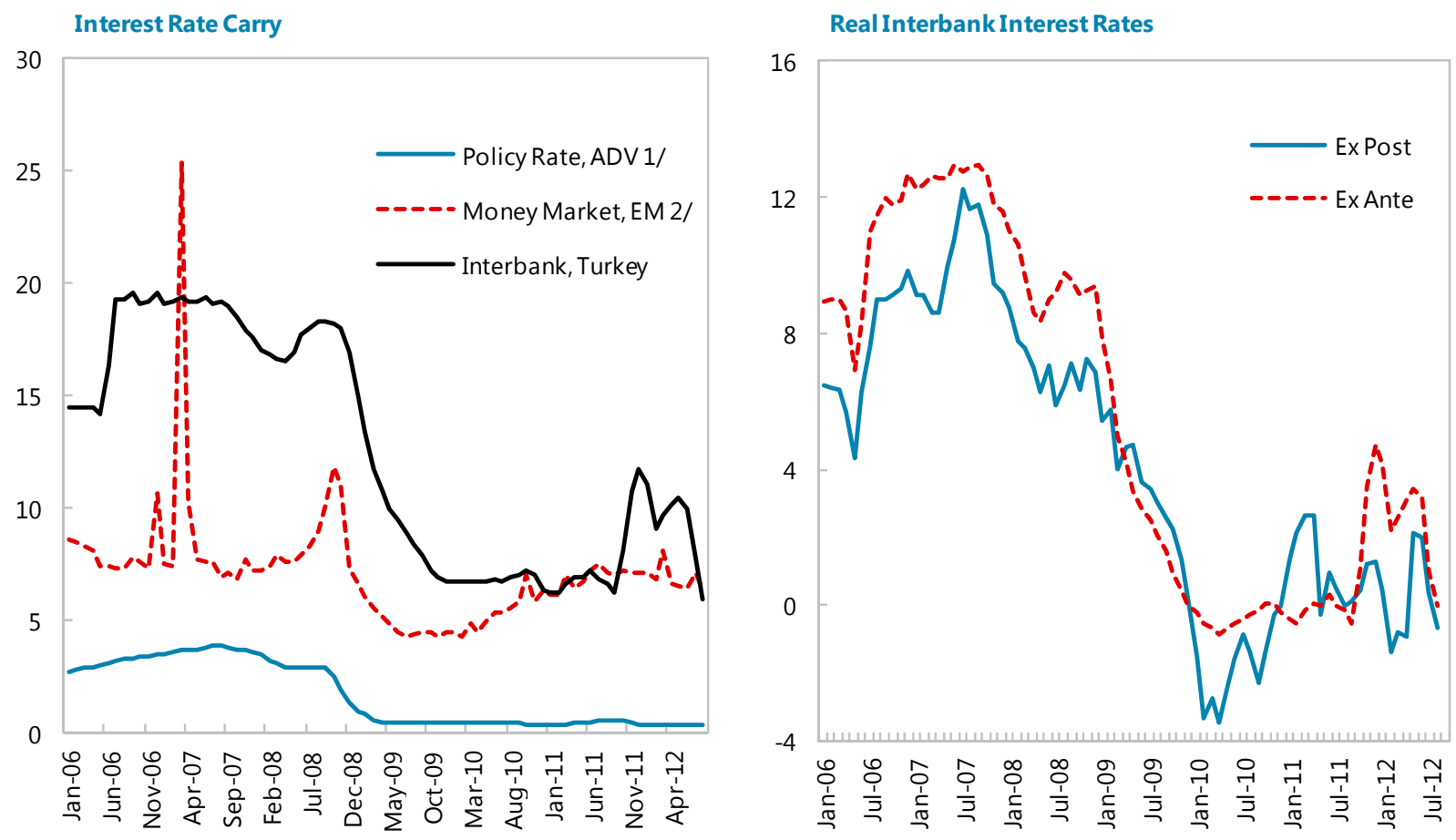

1/ U.S., U.K., Euro area, Japan.

2/ Brazil, Korea, India, Poland.

Sources: CBRT; Haver; IFS; and IMF staff calculations.

38. While it difficult to link this turnaround in the relationship between the real interest rates and the current account to just one factor, there is one obvious change between these two periods, which is the average level of interest rates. Comparing real interbank rateswhether ex post ( 8.5 percent against -0.3 ) or ex ante (11 percent against 0.7 ) —one sees a dramatic loosening. Consequently, a question arises whether monetary tightening at such low rates means much, especially when memories of much higher interest rates are not in a very distant past.

\footnotetext{
${ }^{13}$ It is also interesting to observe that while from mid-2010 till late 2011 the CBRT managed to maintain market interest rates at levels comparable to other emerging markets, afterwards that proved to be insufficient and the interbank rates had to go up above those in other emerging countries.
} 


\begin{tabular}{l|cc|ccc|ccc}
\hline & \multicolumn{2}{|c|}{ Interbank } & \multicolumn{3}{c|}{ Corporates } & \multicolumn{3}{c}{ Consumers } \\
& Nominal & Real & Nominal & Real & Spread & Nominal & Real & Spread \\
\hline $\mathbf{2 0 0 6 - 0 8}$ & 17.8 & 8.5 & 23.9 & 14.6 & 6.1 & 21.7 & 12.5 & 4.0 \\
$\mathbf{2 0 1 0 - 1 1}$ & 7.2 & -0.3 & 12.1 & 4.6 & 5.0 & 19.1 & 11.6 & 11.9 \\
Difference & 10.6 & 8.9 & 11.8 & 10.0 & 1.2 & 2.6 & 0.9 & -8.0 \\
\hline
\end{tabular}

39. It is also interesting to observe how the change in the environment affected various lending rates. In particular, while there is a lot of variability, a comparison of these two periods shows that on average lending rates for corporates have decreased by roughly the same amount as the interbank rates (by 1 percentage point more, in fact), but that consumer rates have declined by much less, and instead the spread against the interbank rates for the latter has substantially increased. ${ }^{14}$
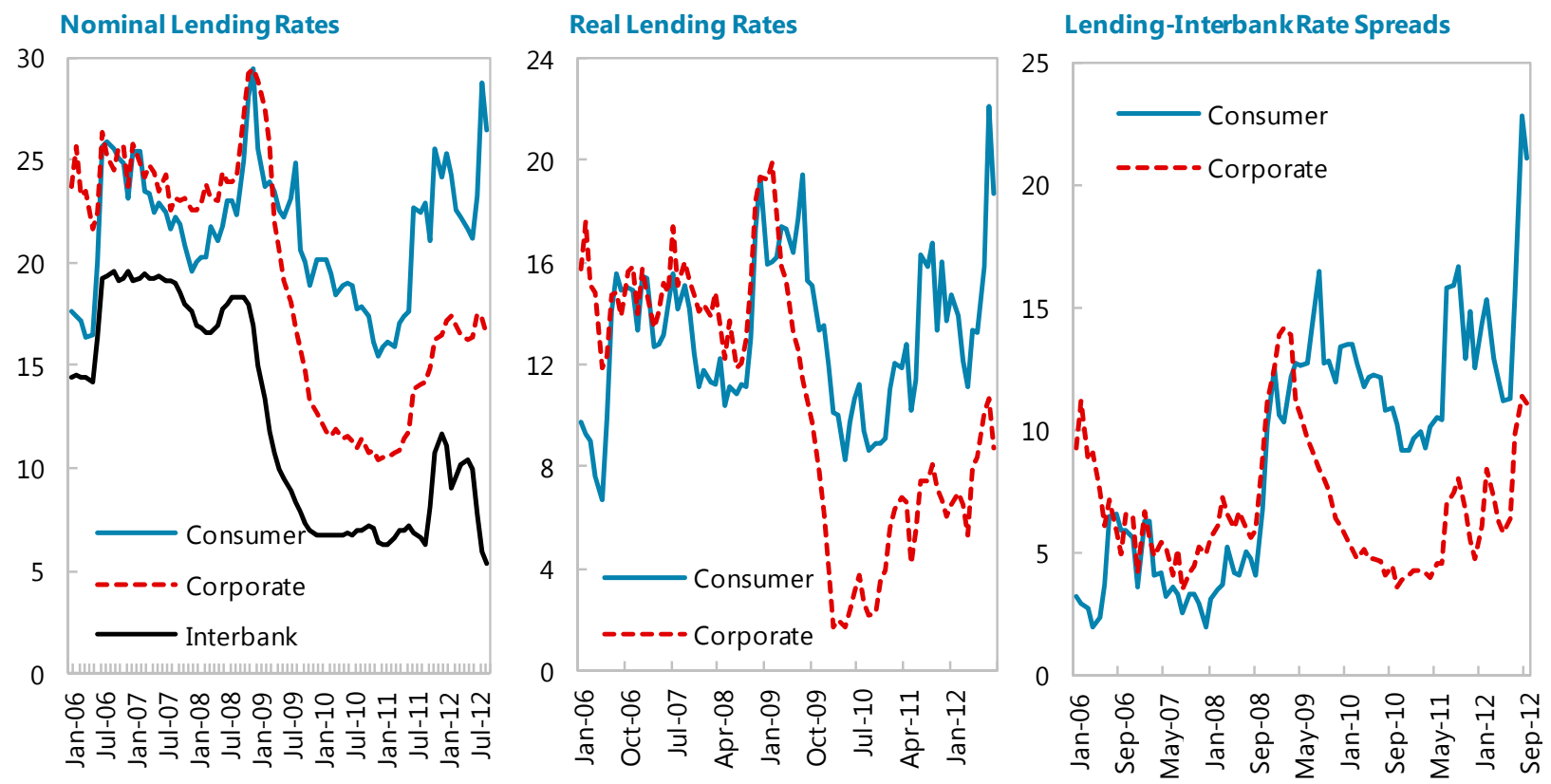

Sources: CBRT; and IMF staff calculstions.

\section{E. Conclusions}

40. Despite the short duration of the CBRT's new framework, which complicates its assessment, its track record is mixed. Its first incarnation, covering the October 2010October 2011 period, did not lead to a timely or significant improvement in either external or internal imbalances. With the adoption of a revised framework in 2012, improvements

\footnotetext{
${ }^{14}$ Since 2009 the consumers no longer have access to FX lending, while corporate still do, which is likely to explain such a divergence in behavior of the spreads.
} 
have been seen on both fronts. However, it is difficult to disentangle whether these improvements have been brought about by the mechanics of the new framework or by tightening of monetary conditions per se in combination with other factors.

41. It remains to be seen how well the current framework will perform in more testing conditions. In particular, in the case of renewed inflows into Turkey-either because of improvements in the global environment or because of Turkey being seen as an attractive destination-would current account deficit continue to shrink and would its financing structure continue to improve? Likewise, in the case of weak inflows or even outflows, would the pressure on exchange rate lead to sizeable depreciation and potentially a loss of reserves? Under both of the scenarios, the ability of the CBRT to achieve inflation target is likely to be weakened, either because of demand-induced pressures in the first case or because of exchange rate pass-through in the second.

42. Ultimately the success of a monetary policy framework is tied to its ability to achieve the inflation target. Today, even though the headline inflation has started to decrease, the core measures and inflationary expectations remain around 7 percent. In spite of an increase in the CBRT's gross reserves, net reserves remain low. Meanwhile, the framework leaves an impression that the CBRT may have growth and exchange rate stability higher on its list of priorities than inflation. The latter, instead of deterring speculative flows, may, in fact, attract them. Finally, transmission to the market rates seems to have weakened.

Subsequently, the CBRT's abilities to guide economy-wide interest rates in a quick and meaningful manner may be undermined. 
Figure 1. CBRT's New Framework
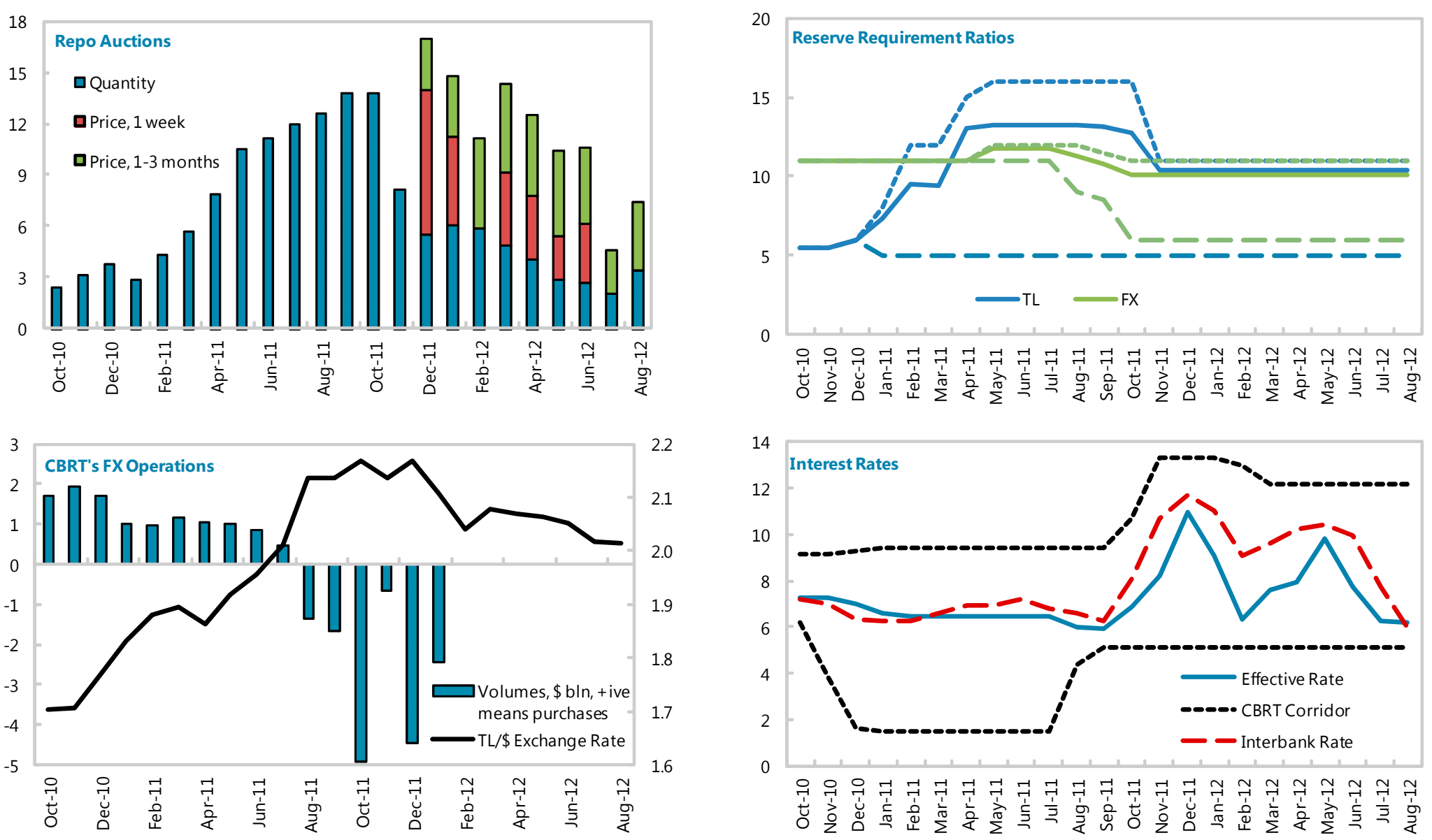

Source: CBRT and IMF staff calculations. 
Figure 2. Turkey: How Successful was the CBRT? 1/
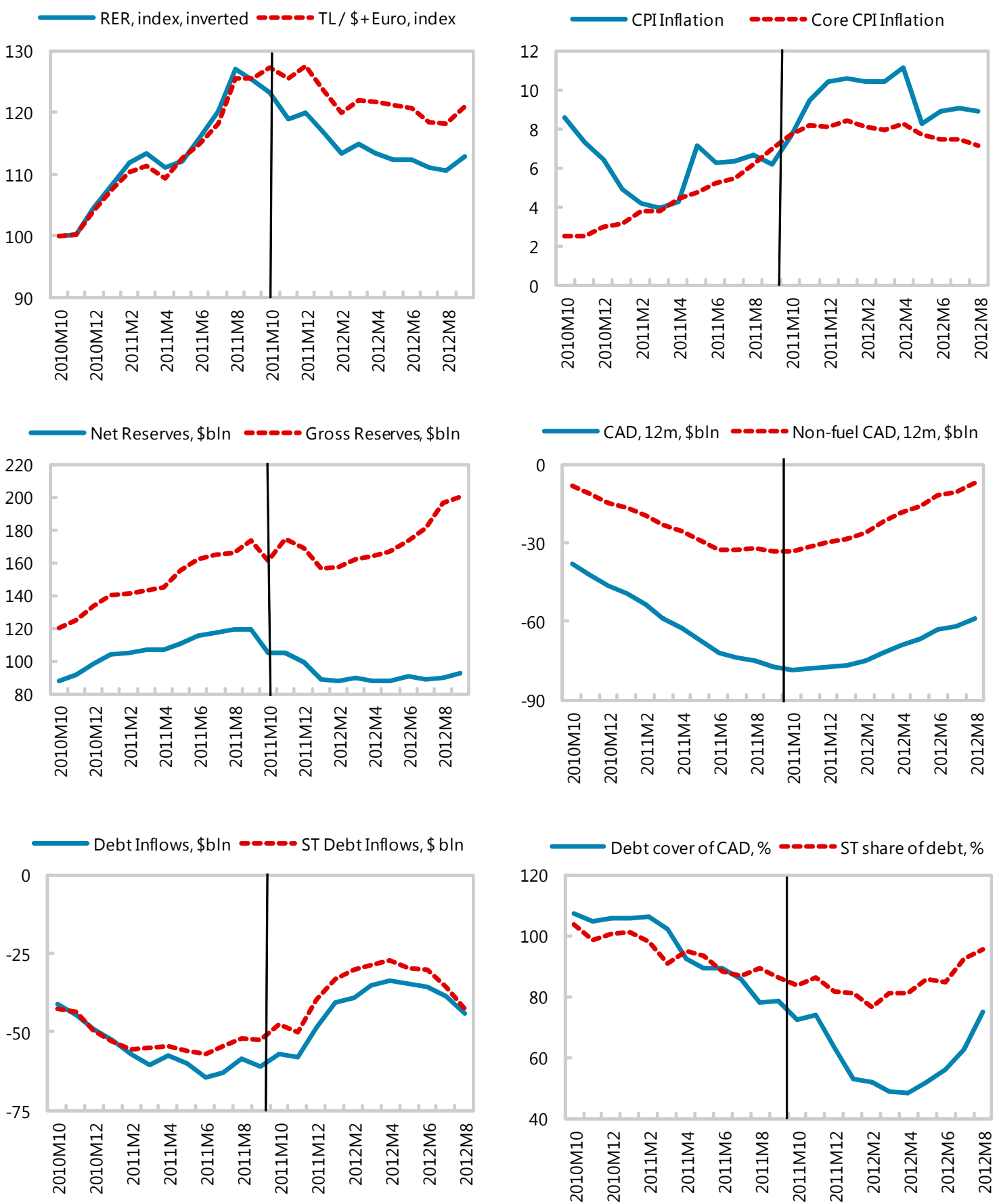

$1 /$ The vertical line separates two different modifictaions of the framework.

Source: Turkstat, CBRT, and IMF staff calculations. 
II. Turkey's Current Account Rebalancing: CyClical or Structural? ${ }^{1}$

After peaking at $\$ 78$ bn (10.2 percent of GDP) in October 2011, Turkey's current account deficit (CAD) is adjusting fast: by June 2012 the 12-month rolling deficit had already shrunk by $\$ 15$ bn to $\$ 63$ bn and the non-fuel deficit had adjusted even more by $\$ 21$ bn to $\$ 12$ bn. The pace at which the deficit shot up in the first place was even more impressive, as the CAD sextupled in less than two years. What are the factors behind the roller coaster ride of Turkey's current account? More relevant at this point, is the ongoing adjustment cyclical or structural in nature?

1. Our analysis of monthly data suggests that 1) Turkey's current account in the long run is closely linked to the state of the economy; and 2) the ongoing adjustment is mostly cyclical and driven by the slowdown in both production and consumer credit growth. Suppressing domestic demand can help but only temporarily; the ultimate conquest of Turkey's large CAD would have to come from improving competitiveness and reducing import reliance.

2. Distinct from standard CGER or EBA analysis, we study the CAD dynamics in a higher frequency setting with richer dynamics and over a policy-relevant horizon. Our sample of monthly current account series and its determinants starts in 2004M1, the earliest date available for consumer credit stock, and goes to 2012M5. The higher frequency setting allows us to study not only the relatively slow-moving long run determinants as in CGER or EBA, but also the short-run dynamics over a policy-relevant horizon. To reduce noise that often comes with higher frequency data, all series are seasonally adjusted with the X11 method where seasonality is a concern.

3. The movement of the seasonally adjusted CAD, denominated in US dollar, appears to be closely aligned with that of three seasonally adjusted variables (panel chart): 1) the aggregate industrial production (IP) index; 2) the annual increase in the stock of credit to household and consumers, including credit card debt; ${ }^{2}$ and 3) oil prices. Unit root tests confirm that all the four series contain unit roots in the sample period. The real exchange rate, usually an I(1) series and an important determinant of the current account, does not have a unit root during the sample period, partly because of the policy engineered depreciation in 2010 and then the inflation induced real appreciation recently.

\footnotetext{
${ }^{1}$ Prepared by Yanliang Miao (SPR)

${ }^{2}$ Alternatively, one could use total credit outstanding to the private sector. But it is potentially highly correlated with IP as the latter is closely linked to corporate sector borrowing. We thus separate consumer credit from corporate credit to capture the demand for imported consumption goods, distinct from the demand for intermediate inputs that is captured by IP.
} 


\section{Co-integrating tests of the four I(1) series support the null that they share at}

least a common stochastic trend. The existence of a co-integrating relationship enables us to study both the long- and short run dynamics in an Error Correction Model (ECM) framework:

$$
\Delta y_{t}=\beta_{1} \Delta x_{t}+\beta_{2} \epsilon_{t}-(1-\alpha)\left[y_{t-1}-\gamma_{1}-\gamma_{2} x_{t-1}\right]+\mu_{t}
$$

where $y_{t}$ is the current account deficit at month $t, x_{t}$ the vector of variables (IP, the annual increase in consumer credit, and oil prices) co-integrated with the current account, and $e_{t}$ the exchange rate which is stationary over the sample period. We experiment with lira/US\$, US\$/Euro, and the real effective rate in fitting the short run dynamics of equation (1).

5. The short run dynamics (Table 1 upper panel): the adjustment in the CAD, $\Delta y_{t}$, in the short run is dominated by domestic consumption (proxied by the rise in the stock of consumer credit) while the impact of IP is economically and statistically insignificant. A one percent rise in the change of consumer credit is associated with a one percent rise in the adjustment of CAD (table 1, column 1). The unit elasticity is remarkably stable regardless of the exchange rate used in different regression specifications (table 1, columns 2-3). The impact of oil prices is not statistically significant, but the short run price elasticity rises to 0.5 or above from its long run counterpart of zero, reflecting the small elasticity of volume response in the short term. The lira/US\$ rate (table 1, column 1) is the only significant exchange rate in the short run, in contrast with the US\$/Euro and the real effective rate. It bears the expected negative sign, supporting the hypothesis that a depreciation of the lira against the US\$ is associated with a reduction in the CAD.

6. The long run dynamics (Table 1 lower panel): when it comes to the long run, the adjustment in the CAD is mainly driven by industrial production and, to a lesser extent, domestic consumption. A one percent rise in the IP index is associated with a 3.4 percent rise in the CAD denominated in US dollar, while a one percent increase in consumer credit is associated with a modest 0.4 percent increase in the CAD (table 1, column 1). Oil prices have no sizeable long term impact, both economically and statistically, reflecting possibly the long standing structural reliance on oil imports and thus muted impact on the level shift of the CAD.

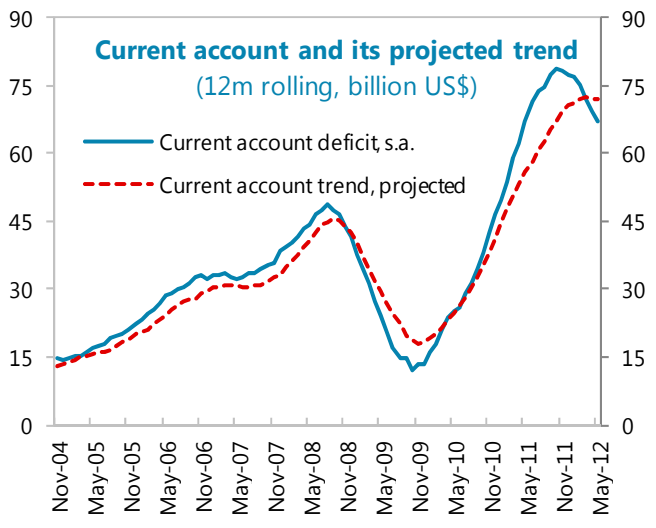

Source: IMF staff calculations Estimating separately the long run co-integrating relationship $\left(y_{t-1}-\gamma_{1}-\gamma_{2} x_{r-1}\right)$, the annualized seasonally adjusted CAD has fallen below its trend level since 2012M3 (text chart), indicating that in large part the recent adjustment corresponds to short run (i.e., cyclical) dynamics. 
7. The long run relationship, however, might be subject to structural breaks.

Standard Chow test and the Bai and Perron procedure identify at least two break points in the $\mathrm{CAD}$ series, one at the onset of the global financial crisis (GFC) and the other in the second half of 2010. Due to the limited observations in the post GFC sample, however, the long run relationship cannot be re-estimated. But there is empirical evidence that the ongoing adjustment is dominated by cyclical factors such as credit growth and the exchange rate. For example, credit related imports such as consumption and capital goods have contracted more than intermediate imports (text chart).



8. The emerging de-coupling between Turkish exports and imports after the GFC could help sustain the ongoing adjustment. Exports and imports had been very well aligned up to the crisis due to the high import content of exports and the fact that 70 percent of imports were intermediate inputs. Export diversification, especially to the MENA region, has gathered pace after the GFC, facilitated by geopolitical factors such as reconstruction in Libya and Iraq and international sanctions against Iran. In addition to market diversification, the accompanying product diversification toward less import-intensive goods-building materials and food products to the Middle East —also helped reducing import reliance.

\section{Despite the budding de-coupling, the ongoing current account rebalancing is} mostly cyclical as the impact of credit growth becomes dominant during the "error correction stage." With the slowing down in credit growth, capital and consumption imports contracted more than intermediate imports. As a result, overall imports were driven to a lesser extent by intermediate imports and, through the latter, became less synchronized with exports. To sustain the ongoing adjustment, continuous export diversification and restraint in credit and domestic demand are necessary. Declining oil prices would help, but the impact would be limited. In contrast, a large turnaround in domestic demand, driven either by capital flows or rapid credit growth, would bring to a halt the rebalancing process. In the long run, the key still lies in reducing the import content of domestic demand and exports and the reliance on oil imports. 
Figure 1. Turkey's Current Account Deficit and Its Determinants
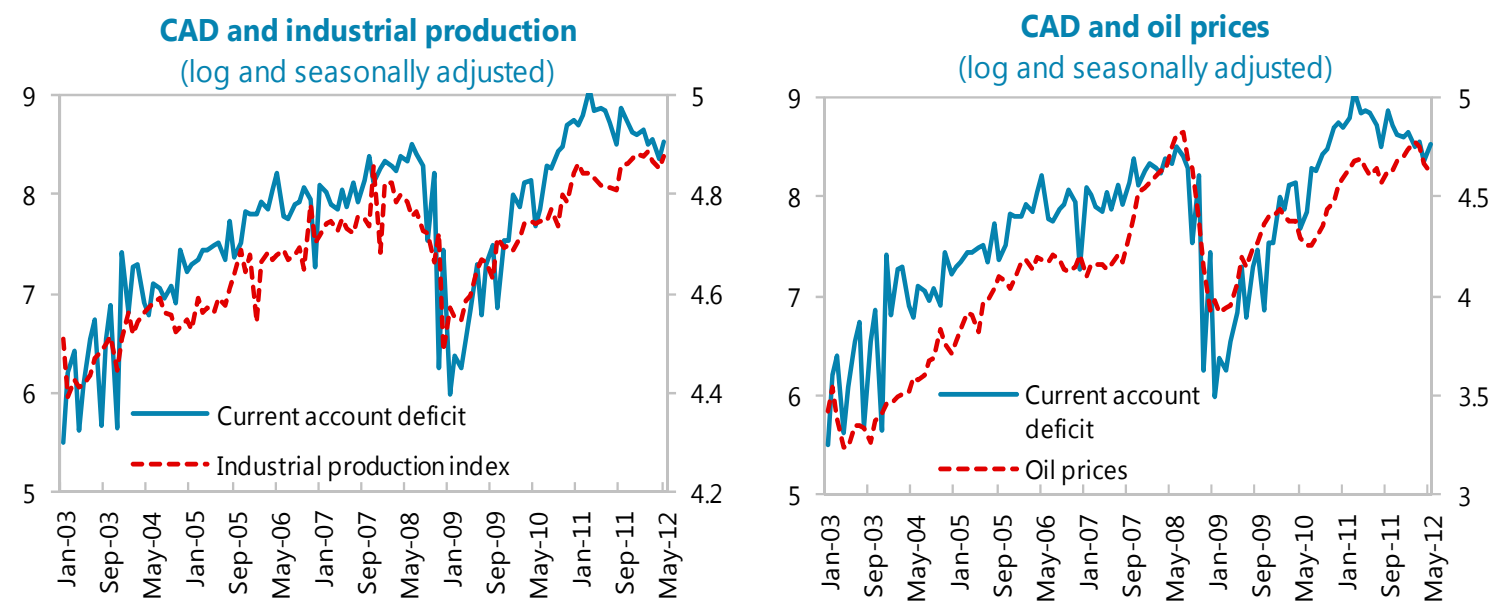

CAD and consumer credit

(log and seasonally adjusted)

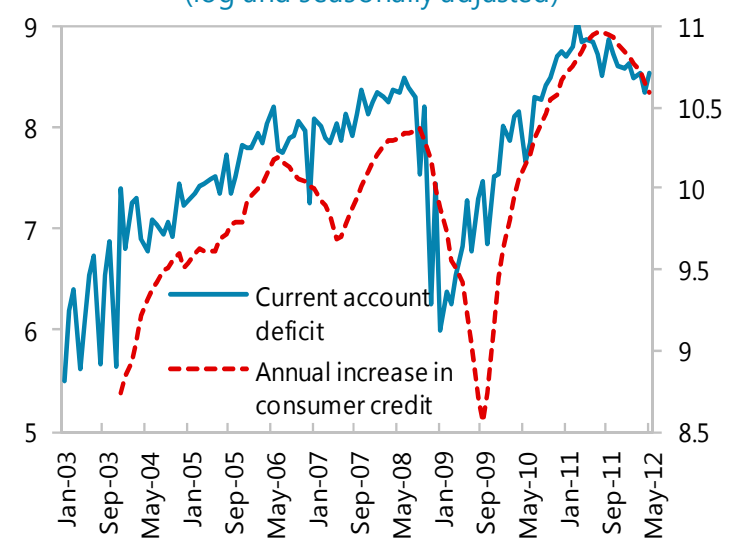

CAD and REER

(log)

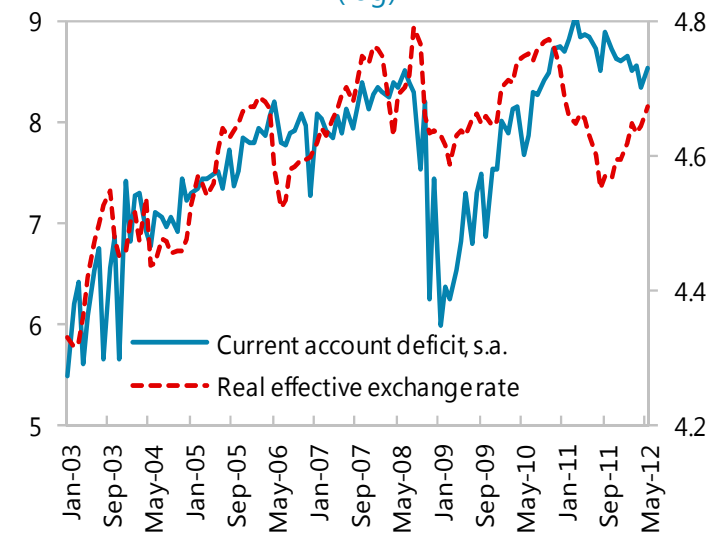

Source: CBRT, Haver, and IMF staff calculations 
Table 1. Turkey Current Account Adjustment Dynamics

\begin{tabular}{lccc}
\hline & $(1)$ & $(2)$ & $(3)$ \\
Variables & Lira/USD rate & USD/Euro rate & Real effective rate \\
\hline & Short run dynamics & & \\
Industrial production, change & 0.450 & -0.234 & -0.249 \\
& $(0.845)$ & $(0.837)$ & $(0.827)$ \\
Consumer credit growth, change & $1.018^{* * *}$ & $1.061^{* * *}$ & $1.046^{* * *}$ \\
& $(0.356)$ & $(0.373)$ & $(0.369)$ \\
Oil price, change & 0.528 & 0.697 & 0.694 \\
& $(0.488)$ & $(0.528)$ & $(0.503)$ \\
Exchange rate & $-0.856^{* *}$ & 0.0886 & 0.191 \\
& $(0.333)$ & $(0.710)$ & $(0.514)$ \\
& Long run dynamics & & \\
Current account, lag & $-0.828^{* * *}$ & $-0.709^{* * *}$ & $-0.708^{* * *}$ \\
Industrial production, lag & $(0.116)$ & $(0.110)$ & $(0.110)$ \\
& $3.397^{* * *}$ & $2.615^{* * *}$ & $2.609^{* * *}$ \\
Consumer credit increase, lag & $(0.894)$ & $(0.875)$ & $(0.869)$ \\
& $0.382^{* * *}$ & $0.277^{* *}$ & $0.279^{* *}$ \\
Oil price, lag & $(0.116)$ & $(0.124)$ & $(0.113)$ \\
& -0.0919 & 0.00441 & -0.0159 \\
Constant & $(0.211)$ & $(0.280)$ & $(0.242)$ \\
& $-12.60^{* * *}$ & $-9.562^{* * *}$ & $-10.33^{* * *}$ \\
Observations & $(3.145)$ & $(3.040)$ & $(3.742)$ \\
R-squared & & & 101 \\
\hline
\end{tabular}

The table regresses the monthly change in seasonally adjusted current account deficit on its long run and short run determinants in an error correction framework. All variables are taken in logs and the estimated coefficients can be interpreted as short run and long run elasticities, respectively. Seasonally adjusted values are used for the industrial production index, the increase in the stock of consumer credit, and oil prices. Standard errors in parentheses $* * *$ $p<0.01,{ }^{* *} p<0.05,{ }^{*} p<0.1$. 


\section{Macroprudential Framework ANd Policies in TURKey ${ }^{1}$}

Turkey's economy has long been subject to boom-bust cycles linked to capital flows. And while the Turkish banking system continues to perform well, it faces some structural vulnerabilities that can pose financial stability risks. In common with peer countries, Turkey has been developing and implementing a macroprudential policy (MPP) framework, which has had some success in mitigating financial stability concerns. Looking ahead, Turkey's macro-prudential and micro-prudential tool kit should be expanded and used in a more targeted and active manner to ensure financial stability, with a focus on debt-to-income limits on households, steps to constrain unhedged foreign exchange borrowing, and more active use of steps to limit growth in very fast-growing credit segments.

\section{A. Background}

\section{Turkey's economy has long been subject to boom-bust cycles linked to capital}

flows. Reflecting in part low domestic savings, Turkey remains heavily dependent on foreign capital, contributing to large real sector volatility. Turkey's gross external financing needs are large, representing roughly a quarter of GDP on an annual basis. The dependence on foreign capital means that when capital inflows slow, economic activity slows sharply, leading at times to hard landings. This in turn can pose risks for financial stability, and underscores the importance of ensuring a sound macroprudential framework

\section{The Turkish banking system continues to perform well, although vulnerabilities}

remain. Relative to peers, banks' profitability remains high; leverage and the level of non-performing loans are low; and capital buffers are strong. Banks have been comfortably rolling over external borrowing notwithstanding the volatile external backdrop, and the banking system short FX position has recently declined. However, the increased dependence of banks on short-term foreign borrowing (over 60 percent of overall bank external funding) represents a rollover risk. In addition, the banking sector loan-to-deposit ratio has surpassed 100 percent from 70 percent a few years ago, and consumer indebtedness relative to disposable income, while lower than in many other developed countries, has risen to 50 percent in the recent credit boom. Corporates are exposed to direct foreign exchange risk with its short FX position totaling $\$ 128$ billion (see figure panel 1 for an overview of banking sector indicators).

\footnotetext{
${ }^{1}$ Prepared by Heiko Hesse (MCM).
} 


\section{B. MPP Framework and Literature}

\section{The objectives and design of an MPP framework}

3. A well-articulated MPP framework is crucial to achieve more effective crisis prevention. The 2007/8 crisis underscored the need for countries to develop a strong policy framework to address macro-financial systemic risks including enhanced prudential regulation, intensified supervision and introduction of new MPP instruments. The MPP framework should enable the authorities to identify the main sources of systemic risk, develop a well-focused policy agenda to mitigate these risks, and provide clarity as to which authorities are responsible and accountability for crisis prevention, ensure a high degree of accountability and willingness to act as well as mutually supportive policies among the relevant agencies while preserving the operational autonomy of established policy fields (see IMF, 2011 and Nier et al, 2011). In addition, the first line of defense for maintaining systemic financial stability should be robust micro-prudential supervision and regulation.

\section{Macroprudential instruments are typically introduced with the objective of} reducing systemic risk, either over time or across institutions and markets (Lim et al, 2011). Countries use a variety of tools, including credit-related, liquidity-related, and capital-related measures to address such risks, and the choice of instruments often depends on countries' degree of economic and financial development, exchange rate regime, and vulnerability to certain shocks. Countries often implement these instruments in combination rather than singly, use them to complement other macroeconomic policies, and adjust them countercyclically so that they act in much the same way as "automatic stabilizers."

\section{Cross-country research by Lim et al, 2011) demonstrates that some targeted risk} variables show a change of course after macroprudential instruments are introduced. An examination of the performance of the target risk variables during the periods before and after the implementation of a macroprudential instrument indicates that a number of them may have had the intended effect. Some credit-related instruments - e.g., caps on loan-tovalue, caps on debt-to-income, dynamic provisioning, and reserve requirements (RR) - seem to have an impact on credit growth. The paper also finds that to address systemic liquidity risk, instruments such as limits on liquidity mismatch may be used, or limits on the net foreign currency position if the liquidity risk stems from foreign currency funding. To address risks arising from excessive leverage, capital-related instruments may be a good choice. These measures provide a buffer that can be made countercyclical through adjustments in the capital requirement, the risk weights of assets or provisioning requirements, and can thus help curtail excessive growth in leverage. If risks arise due to capital flows, all three types of instruments can be used. 


\section{Country experience}

6. Turkey's peer countries have used a similar range of MPP tools to deal with their financial stability concerns, with some also resorting to capital flow measures (CFMs; see Lim et al 2011).

- Brazil: In order to reduce credit growth and curb speculative inflows, Brazil increased RR in 2010 and also introduced a 60 percent unremunerated reserve requirement on banks' short foreign exchange positions in the spot market. The central bank also increased capital requirements for some consumer loan operations with long maturities and high LTV ratios (including car loans) (2010). In October 2009, it also re-imposed CFMs via the IOF on foreign purchases of bonds and equities and extended to foreign borrowings (March 2011).

- $\quad$ Korea: To slow housing market booms, Korea extensively used LTVs and DTIs (which were adjusted according to house price fluctuations) while it also utilized RRs and is currently phasing in a reduction in the loan-to-deposit ratio to 100 percent. During 2009-2011, Korea used a number to measures to reduce the build-up of short-term external debt. For example, it introduced a ceiling on banks' FX forward positions in 2010 while limits were set on FX loans. FX liquidity standards were tightened in 2009 while banks were subject to a macroprudential levy on their non-deposit FX liabilities in 2011. As a CFM, a withholding tax on foreign purchases on treasury and money stabilization bonds was re-introduced.

- Poland: Poland, which faced a credit boom during 2006-2008 and then FX liquidity concerns during the crisis period, aimed to mitigate household credit and FX risks while improving banks' capital and liquidity buffers. From 2010, scenario-based DTIs to households were introduced which were stricter for FX loans. Poland also amended the risk weights on Polish zloty and FX loans while restrictions were imposed on profit distributions in 2009.

\section{Turkey's MPP Measures and Framework}

7. Turkey has made active use of MPP measures, notably since the Lehman crisis, to safeguard the domestic financial sector (Annex 1). In October 2008, banks dividend payouts were sharply curtailed to bolster bank retained earnings and capital. In January 2009, the BRSA loosened FX liquidity requirements while restructured loans were reclassified 
from 'overdue' to 'performing' under certain conditions. ${ }^{2}$ Banks were also prohibited, starting in June 2009, from lending in FX (or FX-indexed loans) to consumers while from March 2010 onwards banks temporally lowered their new general provisioning rate for cash loans. Although the IMF recommended an earlier termination of regulatory forbearance measures, the phase-out only occurred in March 2011 when the credit boom was well underway.

\section{From 2010, a credit boom took off in Turkey, for which the authorities then} resorted to additional MPP instruments, albeit with a delay (Annex 2). Initially, the steps were taken primarily by the CBRT, which relied—starting in late 2010 - on successive increases in RRs to temper loan growth. However, this measure proved largely ineffective as the CBRT offset the higher RR by injecting additional liquidity via open-market operations. The authorities also used moral suasion to target a uniform 25 percent increase on banks' annual loan growth for 2011, adjusted for exchange rate movements, which appeared to have become binding for some banks by mid 2011. More importantly, starting in June $2011,{ }^{3}$ the BRSA - motivated by macroprudential concerns - increased risk weights for new general purpose (consumer) loans and raised general provisioning requirements for banks with high levels of consumer loans or non-performing consumer loans. These June 2011 measures, together with the implicit nominal credit growth target and the worsening external market conditions, contributed to the sharp slow-down in credit growth in the second half of 2011. The BRSA also limited credit card payments in July 2011, and augmented minimum capital requirements for banks with strategic foreign shareholders (effective January 2012).

\section{The recent improvements in Turkey's MPP framework have drawn on}

recommendations of the 2011 FSAP update. In addition to the steps cited above, in June 2011 a new Financial Stability Committee (FSC) was created by a decree law. The FSC is chaired by the Minister in charge of Treasury - currently the Deputy Prime Minister - and also comprising Treasury, the BRSA, the Capital Markets Board (CMB), the CBRT and the Savings Deposit Insurance Fund (SDIF).

\section{Following the FSAP, the CBRT in October 2011 introduced a new RR}

framework whereby banks have been progressively allowed to meet TL RR by posting FX and gold. The share of TL RR that can be met by using FX been steadily raised, and banks are now able to use up to 60 percent of TL required reserves with FX and 30 percent with gold. In addition, the CBRT is now applying a varying "Reserve Option Coefficient (ROC)" that requires a higher equivalent amount of FX or gold to meet a given portion of TL

\footnotetext{
${ }^{2}$ NPLs peaked in October 2009 at 5.4 percent for all loans and 12.1 percent for consumer credit cards. NPLs would likely have been 1-1.5 percentage points higher at their peak in the absence of the forbearance measures related to loan classifications.

${ }^{3}$ The BRSA had taken some steps when it introduced de jure loan-to-value limits on real estate loans in December 2010.
} 
RR. ${ }^{4}$ Given the large opportunity cost difference between banks' TL and FX funding, banks' participation has been over 90 percent of the maximum allowable amount. The CBRT aims to use this fine-tuning ROC tool for capital flows and financial stability purposes. In principle, this tool will absorb FX inflows, while increasing banks' FX liquidity buffers and the CBRT's gross reserves.

\section{A 2010 IMF survey showed that Turkey's use of MPP instruments has been} broadly in line with other EMs, with some exceptions (see Lim et al, 2011 and Annex 3). At that time, Turkey's main MPP instruments were caps on LTVs, prohibition on FX lending to households, net open FX limits and restrictions on profit distributions, all instruments that have been utilized by other EMs to varying degrees. Turkey's frequent use of RRs from the end of 2010 and especially in 2011 was not captured in the 2010 survey, but many EMs likewise appear to have made intense use of such RR MPP instruments. It is interesting that only a few EMs used caps on FX lending and profit distributions restrictions, instruments that have been important for Turkish banks. Unlike Turkey, many EMs have utilized DTI limits as well as countercyclical capital and dynamic provisioning MPP instruments. As of today, Turkey does not have a formal DTI limit, and provisioning requirements only embedded some countercyclical element when provisioning requirements for consumer loans were raised in June 2011. Turkey's tight limitations on dividend payouts to build up capital buffers could be seen as having a similar impact as the countercyclical capital MPP instrument other EMs have utilized.

\section{Expanding the Tool Kit}

\section{The 2011 FSAP update made a number of recommendations to strengthen the} organizational aspects of its MPP framework. It was suggested to increase emphasis on communication to help ensure accountability for macroprudential policy. Consideration could be also given to establishing more clearly distinct arrangements for crisis prevention (macroprudential policy) and crisis management. In addition, a leading role of the CBRT on the macroprudential committee is useful to harness the central bank's expertise in risk assessment and its incentives to maintain financial stability. The FSAP also suggested enhancing interagency coordination while maintaining operational autonomy of the participating agencies.

13. Looking forward, the authorities could consider implementing in a pre-emptive and targeted manner a wider set of MPP instruments to ensure financial stability. In particular, macro-prudential and micro-prudential policy measures could be considered to maintain systemic financial stability by preempting surges in credit, discouraging banks from

\footnotetext{
${ }^{4}$ For instance, for the increment from 55 to 60 percent of the TL RR that can be satisfied with FX, the ROC is 2.3 versus 1.4 for the $0-40$ percent TL RR bucket.
} 
funding their loan activities via increased short-term FX borrowing, and limiting unhedged FX borrowing by the corporate sector. A more countercyclical and targeted macro-prudential policy approach would also complement fiscal and monetary policy, which, respectively, have been underutilized and overburdened. The sequencing and calibration of any new measures will need care, so as to avoid unintended deleveraging. While it is not advocated that all the below measures be swiftly implemented, the authorities could consider the application of such macro-prudential and micro-prudential policies should the above-mentioned broad areas of risks and financial stability become a policy concern. In particular, safeguarding systemic financial stability also requires robust micro-prudential regulation and supervision.

\section{Existing capital buffers will have to be conserved. The BRSA has fully}

implemented Basel II as of June 2012, which also includes Basel II.5 provisions (CRD III), ${ }^{5}$ and would be ready for Basel III implementation from the beginning of 2013. ${ }^{6}$ Turkish banks have maintained a comfortable capital adequacy ratio of 16.3 percent (which dropped by only 0.2 percentage points from implementation of Basel II) and tier 1 capital at 14.1 percent (both above peer countries). It would be important to phase-in Basel III (capital, liquidity and leverage rules) according to the agreed schedule, or even on an accelerated basis given that results of quantitative impact studies (QIS) have been promising so far, especially compared with peer countries. For instance, banking sector leverage remained strong with around 8 percent (Basel III definition). Turkey's minimum capital target of 12 percent as well as tight dividend payout rules are useful micro-prudential measures in an environment of strong credit growth, since capital buffers can erode quickly when banks expand their balance sheets towards higher risk-weighted loans.

\section{While the Turkish banking sector has been comfortably rolling over external funding during the global financial crisis, it faces some structural FX funding challenges that could be addressed with macro-prudential and micro-prudential} measures. Although direct parent funding is low, Turkish banks are vulnerable to a capital flow reversal. The banking sector loan-to-deposit ratio has risen above 100 percent from 70 percent a few years ago, and while deposits constitute the bulk of bank liabilities, the share of wholesale and foreign currency funding has increased sizably over the last two years. ${ }^{7}$ To counter such increasing structural funding maturity and FX mismatches, the

\footnotetext{
${ }^{5}$ The negative impact on capital was marginal with 0.2 percent, mainly driven by the zero risk weight on FX RR held with the CBRT.

${ }^{6}$ The BRSA is focusing on compliance with the EU rules CRDIV. It plans to finish drafts of the Basel III regulation by end 2012. Given that over 90 percent of capital buffers are core tier 1 capital, the BRSA argued that it would not need a long Basel III phase-in period.

${ }^{7}$ In June 2012, external borrowing represented about 15 percent of the overall banks' liabilities with 62 percent of the \$106bn external bank debt maturing in less than a year. The majority of this external borrowing comes in the form of loans (43 percent), followed by repos, deposits, and syndicated loans (about 15 percent each).
} 
BRSA could introduce minimum FX liquidity ratios at the 3-month and longer horizons to extend funding duration. The authorities could also phase in the Basel III liquidity rules according to the agreed schedule or even accelerated, given promising QIS results, once a Basel agreement on the final rules has been reached. As in the existing liquidity regulation framework in Turkey, the Basel III liquidity rules could be separated by currencies. In addition, the targeted application of FX RR increases at shorter maturities as a MPP measure could also slow down banks' short-term external borrowing in case of excessive FX mismatches. ${ }^{8}$ As with all RR increases, the aim is to increase the spread between loan and deposit rates and thus help to lower loan growth. ${ }^{9}$ The experience of other peer countries that had to deal with excessive FX funding could be also useful. For instance, Korea had adopted a number of quantity MPP measures such as a move to a 100 percent loan-to-deposit ratio, a ceiling on banks' FX forward positions, limits on FX loans or a levy on non-deposit FX liabilities.

\section{Additional steps to limit unhedged FX borrowing by the corporate sector may be} warranted. While households are long FX, with almost no FX liabilities, non-financial corporates are exposed with a short FX position totaling $\$ 126$ billion. FX corporate loans comprise around 26 percent of banks' total loan portfolio and 40 percent of corporate loans. Banks usually do not lend in FX to the smaller SMEs, and require corporates to have FX export income or collateral. Moreover, additional buffers include FX corporate assets and personal FX accounts of corporate owners, both held abroad (but for which little data is available). Nonetheless, the short FX position of the corporate sector does pose a risk to financial stability, both because of any remaining unhedged corporate exposures, and via a rapid deterioration in banks' asset quality in the event of a depreciation. To this end, a draft BRSA regulation on credit risk management should be finalized, as it would improve banks' risk management and help supervisory examination of banks' FX lending practices. Little information on corporate FX hedging is available, and this data gap should be filled. Higher risk weights and provisioning on unhedged FX lending to corporates could be introduced if growth in this lending segment were to pick up rapidly, especially amidst a capital inflow surge. Data availability would be an important prior condition for such a measure. It may also be desirable to tighten the conditions under which non-FX earning corporates can

\footnotetext{
${ }^{8}$ In addition, in case the CBRT FX RR framework encourages banks to borrow short-term FX; this should be discouraged.

${ }^{9}$ Given banks are increasingly using the CBRT FX RR framework for transforming their FX into TL funding for loans, the cross-currency swap market volume has been also somewhat impacted. Hence, explicitly putting a relative quantity cap on banks' ability to access the cross-currency swap market is not needed at this current juncture. Repeated rollovers of funding swaps with a shorter maturity than the duration of assets could expose banks to interest rate risk. Counterparty risk with European banks is less of an issue than underlying swap interest rate or rollover risks. While swap contracts are done on an OTC basis, counterparts typically have credit support annex (CSA) agreements and daily margining between each other to mitigate credit risks.
} 
borrow FX in Turkey. ${ }^{10}$ If in a situation of excessive FX borrowing by corporates price-based tools do not succeed in curbing corporates' appetite for cheap FX loans, quantity-based tools could be useful as well. For instance, Korea introduced limits on FX hedging by corporations relative to their export earnings in June 2010, while India increased restrictions on external borrowing in December 2009 by, for example, introducing interest rate caps on eligible external commercial borrowing.

\section{Setting a consumer debt-to-income limit (DTI) across the banking system could} sustain household balances' resilience. Unlike some peer countries, Turkey has not suffered a real estate boom and bust in recent years. Household credit in FX is forbidden (since 2009) while LTV ratios on mortgages have been implemented in December 2010 at a 75 percent ceiling. Banks already apply DTI requirements for their internal risk management and credit scoring, and a debt-to-income ratio exists for credit cards (a limit of two times salary for new cards). But household debt, while still lower than in many other developed countries, has significantly increased to around 50 percent of disposable income during the recent boom phase. As is common in some other peer countries (e.g., Korea, Poland or Russia), the BRSA could introduce a DTI for consumers to prevent any excessive growth in consumer indebtedness relative to disposable income. Data collection on consumer income will need to be improved, however, given that consumer income plays no role in the credit score calculated by the credit bureau KKB. ${ }^{11}$ While according to Crowe et al (2011), a DTI can limit household leverage, the calibration could be difficult. The measure can be subject to circumvention (e.g., migration of borrowers to the shadow banking system), and might hit poorer families disproportionally. Hence, it will be important for the KKB and banks to have access to reliable consumer income data.

\section{Using standard prudential policy and regulation, the authorities should be} vigilant against any worsening of credit quality especially given the currently historically low NPL level of 2.8 percent (August 2012). NPL ratios are traditionally backward-looking indicators. Banks have been able to write-off some NPLs by selling them

\footnotetext{
${ }^{10}$ In line with the 2009 legislative change, the average maturity is at least one year with a minimum credit amount of $\$ 5 \mathrm{~m}$.

${ }^{11}$ Turkey has two important credit bureaus, the Credit Bureau of Turkey (KKB) and the Credit Registry at the Central Bank. KKB, established in 1995, is a private company owned by 9 major banks in Turkey, and shares information among member banks and consumer finance institutions, leasing and factoring companies. It disseminates information both on individuals and legal entities for credit purposes. As at end 2011, KKB had 102 members. Data contributing members provide both positive and negative data on consumer and commercial credits, which are updated at monthly intervals. KKB preserves credit history up to five years after closure. The Credit Registry at the Central Bank collects and disseminates credit information pertaining to both individuals and firms, from both bank and non-bank credit institutions, such as leasing and factoring firms. By the recent amendment to the Banking Law, a newly established Risk Center will be transferred to TBA Risk Center. It is eventually projected that the Risk Center signs an agreement with KKB for it handle the former activities.
} 
to NPL companies (independent of the banks). If the future loan growth is too strong in particular segments, the BRSA could consider higher risk weights and/ or provisioning in these segments in a pre-emptive and targeted manner (as was done in June 2011 for consumer loans). As in other countries (e.g. Brazil and Korea), LTV ratios could be more extensively used in specific loan categories such as car loans. Given the high penetration of credit cards in Turkey (close to 5 percent of GDP) compared to other countries and the relative size of credit card lending in banks' loan books (26 percent of retail loans), it would be important to guard against any deterioration in lending standards in this segment or sharp increase in credit card NPLs in a downside scenario. Consumer credit card NPLs peaked during the last crisis at 12.1 percent in October 2009 compared with the current 5.9 percent in August 2012. Data availability and usage on restructured loans by the KKB could be improved especially mapping restructured loans to originating loans in the KKB database.

\section{E. Conclusion}

\section{Turkey has already successfully implemented a sound MPP framework, and this} can be strengthened in specific areas. This note examined the MPP framework in Turkey, with a particular focus on cross-country comparisons and forward-looking pre-emptive and targeted policies the Turkish authorities could implement to maintain systemic financial stability. Following the FSAP, staff emphasized the importance of micro-prudential policies such as application of Basel II and the phase-in of Basel III (capital, liquidity and leverage rules) according to the agreed schedule. Looking forward, the MPP tool kit could be expanded and used in a more targeted and active manner for financial stability. Within a well-articulated macro-prudential framework distinct from crisis management, macroprudential and micro-prudential measures could be considered to maintain systemic financial stability by preempting resurgence of a credit boom, discouraging banks from funding their loan activities via increased short-term FX borrowing and limit unhedged FX borrowing by the corporate sector. 


\section{REFERENCES}

Crowe, C., G. Dell'Ariccia, D. Igan, and P. Rabanal "Policies for Macrofinancial Stability: Options to Deal with Real Estate Booms," IMF Staff Discussion Note 11/02.

International Monetary Fund (2011) “Macroprudential Policy: An Organizing Framework”.

Nier et al (2011), "Institutional Models for Macroprudential Policy, IMF Staff Discussion Note 11/18.

C. Lim, C., F. Columba, A. Costa, P. Kongsamut, A. Otani, M. Saiyid, T. Wezel, and X. Wu (2011) "Macroprudential Policy: What Instruments and How to Use Them? Lessons from Country Experiences," IMF Working Paper 11/238. 
Figure 1. Turkey: Financial and Corporate Sectors
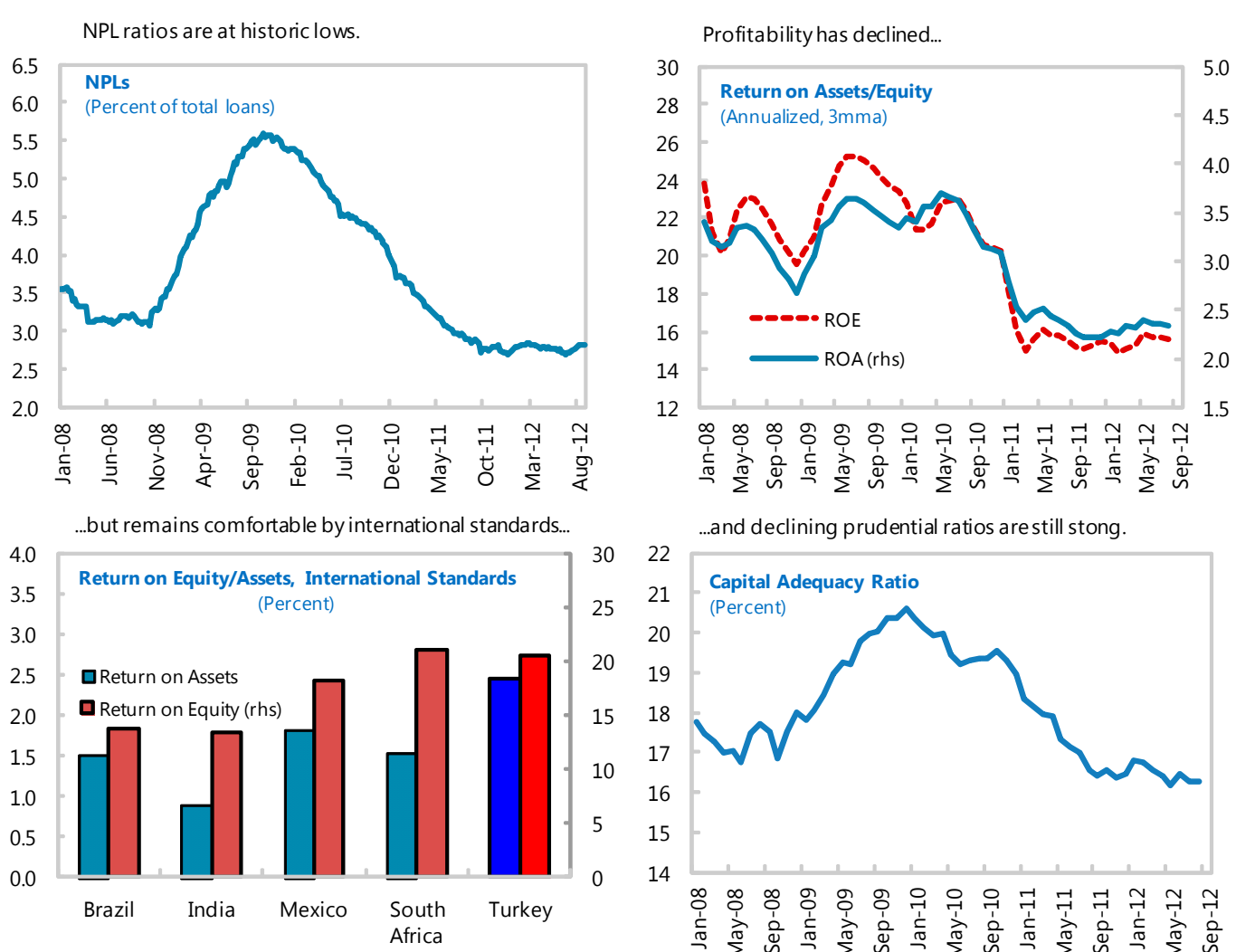

...and declining prudential ratios are still stong.

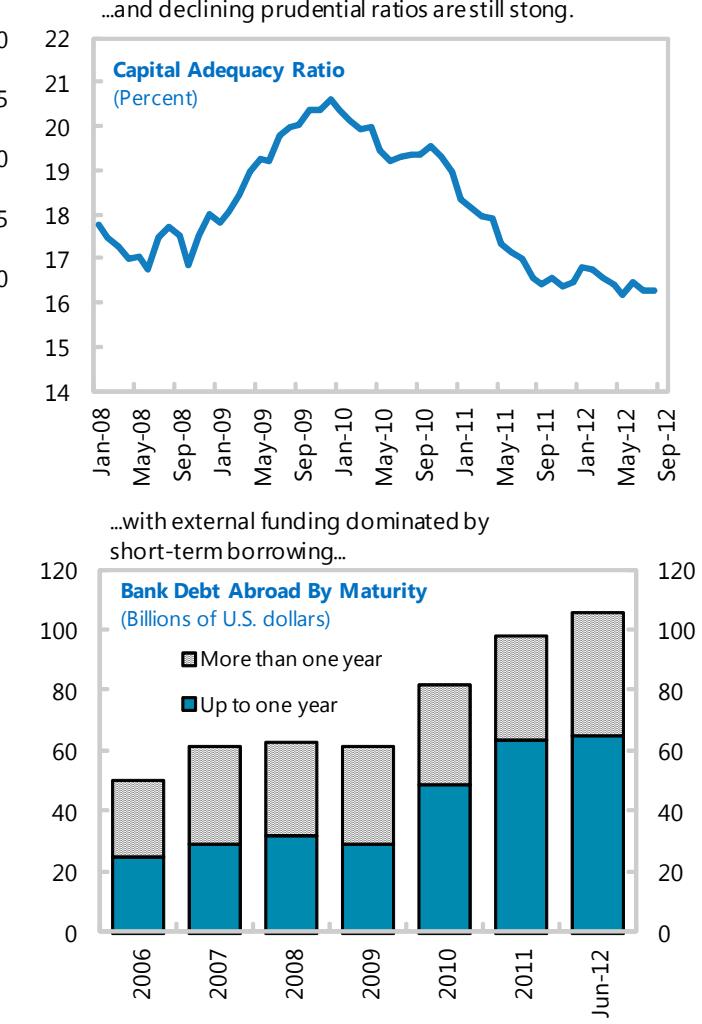

However, the loan-to-deposit ratio has increased
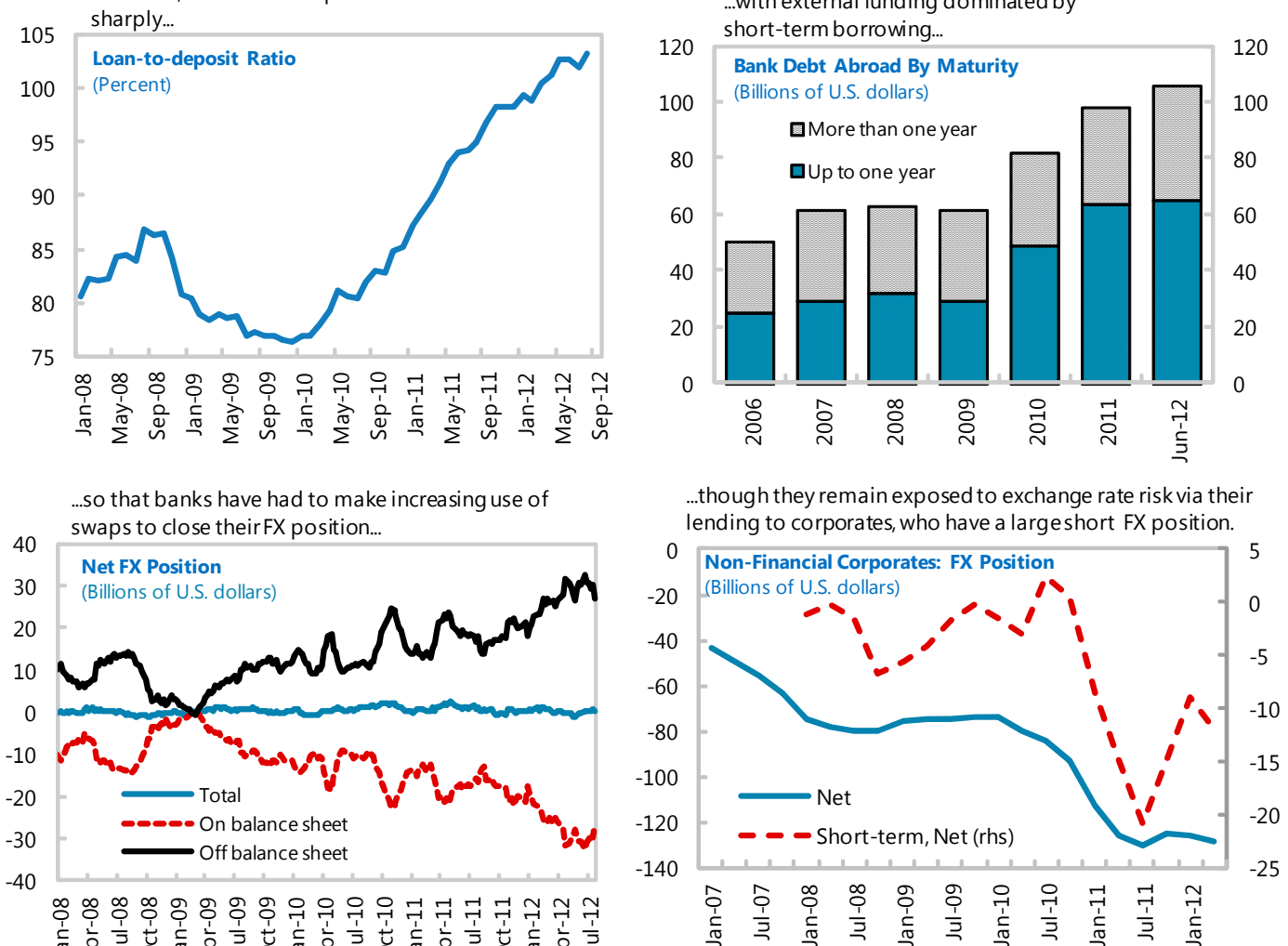




Source: Haver; CBRT; BRSA. 
Annex 1. Main Crisis-Related Measures in 2008/2009

Measure
$\begin{aligned} & \text { Reclassification of banks' holdings of } \\ & \text { government securities }\end{aligned}$

Description

Adoption Date

government securities

Dividend

Reclassification of restructured loans

FX liquidity requirements

Restrictions on FX lending

General provisioning on new loans
Allowed banks to reclassify on a one-time basis their available-for-sale securities to hold-to-maturity status, or fair value through profit or loss, consistent with changes in international accounting standards, thereby avoiding the need for mark-to-market pricing and recording capital write-downs when securities prices fall.

Requires banks to seek approval from the BRSA before distributing dividends. The maximum dividend payout for CAR $>18$ percent is 20 percent, for 16 percent $<$ CAR $<14$ percent is 15 percent and for 13 percent $<$ CAR $<16$ Percent is 10 percent.

Allows banks to reclassify loans from "less than 90 days overdue" to "performing" if: (i) the debtor falls behind because of a "temporary liquidity crunch"; (ii) the loans are restructured; and (iii) a minimum of 3 installment payments-amounting to at least 15 percent of the restructured loan-are subsequently paid; TL 11 billion in loans (about 3 percent of total loans) were restructured under this provision through March 2010. 1/

FX-indexed assets and liabilities could be counted toward the FX liquidity requirement with a coefficient of 45 percent, allowing banks to achieve the required ratio more easily. Coefficient on some government securities items raised.

Allows non FX-earnings companies to borrow in FX from local banks (previously, only FX-earning companies could borrow $\mathrm{FX}$ ), provided $\mathrm{FX}$ loan amount is greater than US\$5 million and average maturity date is longer than a year; bans consumers from taking out FX-linked loans.

Allows banks with CARs above 16 percent (nearly all banks) to lower their general provisioning rate from one to zero percent for cash loans other than credit cards until March 2011; this provisioning rate had been increased from 0.5 to 1.0 percent as a measure under the last SBA.
October 2008

October 2008; extended in 2010 for 2009 profits: and again in 2011

January 2009; extended in March 2010 for another yea

January 2009; still in effect

June 2009

March 2010, effective till March 2011

1/ However, in some banks, up to 20 percent of loans benefited from restructuring 
Annex 2. Recent Macroprudential Measures

\section{Measure}

Loan-to-value (LTV) ceilings

Implicit Nominal Credit Growth Target

High risk weights for consumer loans

Increased provisions for consumer loans

Limits to credit card payments

Interest Rate Risk

Changes to minimum Capital Adequacy Requirements

Changes to deposit insurance premiums
Description

Adoption Date

Implements loan-to-value ceilings on housing loans to

December 2010

consumer (at 75 percent) and on purchases of commercial real estate (at 50 percent).

The authorities provided guidance to banks that credit growth (adjusted for FX movements) in 2011 should not exceed 25 percent.

Higher risk weights introduced for fast growing consumer loans. For new general purpose loans with maturities below two years, the risk-weighting increased to 150 percent (from 100 percent). For new general purpose loans with maturity greater than two years, the risk-weight increased to 200 percent (from 100 percent).

For new (performing) general purpose loans, general provisions were increased from 1 percent to 4 percent. Specific provisions for (pre-nonperforming) loans increased from 2 percent to 8 percent. The higher provisioning requirements are conditional on banks having a consumer loan portfolio exceeding 20 percent of total loans or having a general purpose loan NPL greater than 8 percent.

If three or more monthly payments within a calendar year are less than half of the outstanding balance for the period, the individual credit card limits cannot be increased and cash advances for such credit cards cannot be permitted, unless the outstanding balance for the period is fully covered.

Announced by the BRSA to contain interest rate risk through capital changes on large maturity mismatches, discouraging duration gaps. Effective from 2012.

Amended by the BRSA in September 2011 to apply to banks with foreign strategic shareholders as of January 2012. The minimum ratio would depend on various factors such as the CDS spread of the parent and its sovereign, EBA stress test results and the public debt ratio in the country of origin.

SDIF introduced a premium surcharge for large banks and a new factor to calculate the banks' score for the deposit premium determination.
Spring 2011

June 2011

June 2011

June 2011

August 2011

September 2011

September 2011

Source: Turkish authorities; and IMF staff. 


\section{Annex 3. MPP Instruments and Intensity of Use}

\begin{tabular}{|c|c|c|c|c|c|c|c|}
\hline $\mathrm{Sco}$ & \multirow{7}{*}{ 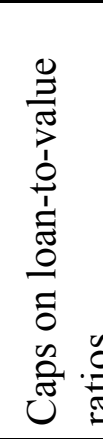 } & \multirow{7}{*}{  } & \multirow{7}{*}{  } & \multirow{7}{*}{  } & \multirow{7}{*}{ 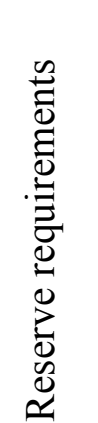 } & \multirow{7}{*}{ 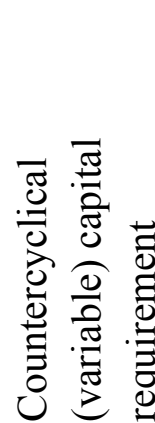 } & \multirow{7}{*}{ 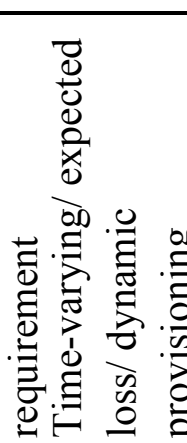 } \\
\hline 1 & & & & & & & \\
\hline 2 & & & & & & & \\
\hline 3 & & & & & & & \\
\hline & & & & & & & \\
\hline 5 & & & & & & & \\
\hline & & & & & & & \\
\hline
\end{tabular}

\begin{tabular}{|l|l|l|l|l|l|l|l|l|l|l|}
\hline Brazil & & & & & & & & & & \\
\hline Chile & & & & & & & & & & \\
\hline Colombia & & & & & & & & & & \\
\hline Mexico & & & & & & & & & & \\
\hline China & & & & & & & & & & \\
\hline India & & & & & & & & & & \\
\hline Russia & & & & & & & & & & \\
\hline South Africa & & & & & & & & & & \\
\hline Poland & & & & & & & & & & \\
\hline Turkey & & & & & & & & & & \\
\hline Korea & & & & & & & & & & \\
\hline US & & & & & & & & & & \\
\hline UK & & & & & & & & & & \\
\hline Japan & & & & & & & & & & \\
\hline France & & & & & & & & & & \\
\hline Germany & & & & & & & & & & \\
\hline Italy & & & & & & & & & & \\
\hline Spain & & & & & & & & & & \\
\hline
\end{tabular}

Source: Lim et al (2011).

Note: No color represents no use of instruments, and ' 1 ' denotes the use of a single instrument. For each of the following attributes, i.e., multiple, targeted, time-varying, discretionary and used in coordination with other policies, the value of ' 1 ' 'is added. 


\section{BOosting SAVINGS In TURKeY ${ }^{1}$}

Turkey's saving rate has fallen dramatically over the last fifteen years, the largest decline of any G-20 country. The decline was concentrated in the private sector, with public savings actually increasing over the period. Low domestic savings have left the country very dependent on volatile foreign capital to finance investment, and hence prone to boom-bust cycles. Raising savings is thus a key medium term objective. In addition to the recent reform of private pensions, achieving this objective will require an improvement in the structural fiscal balance, increases in mandatory savings via the pay-as-you-go pension system, and continued efforts to tackle informality and boost the female labor participation rate.

\section{A. The Issues}

\section{What happened to savings in Turkey?}

\section{Turkey's national saving rate has} fallen dramatically over the last 15 years, from some 25 percent of GDP in the late 1990 s to less than 15 percent of GDP now. Most of the decline occurred before 2003. Modest gains over the last two years are encouraging, but they have yet to make up for the loss in savings in the aftermath of the global financial crisis.

\section{The decline in national savings is} striking by international standards. Looking at the last twenty years, Turkey has had the largest decline in savings of any G-20 country. The decline has been larger than in advanced economies which have, like Turkey, suffered from higher commodity prices, but which have not enjoyed the doubling of income levels - and the boost in savings it carries - that Turkey did. And while the terms of trade can explain why some peer emerging economies have experienced an increase in savings over the period, it is noteworthy that several emerging economies that are not big commodity producers have not seen anything like Turkey's savings decline. In Poland, savings have been remarkably flat over the last fifteen years. In India, savings have declined in recent years but only after a very sharp increase earlier on, so that savings are now significantly higher than in the late 1990s. In these two countries, saving levels are well above those in Turkey, by close to 5 percentage points of GDP in Poland, and 15 percentage points of GDP in India.

\footnotetext{
${ }^{1}$ Prepared by Jacques Miniane (EUR)
} 


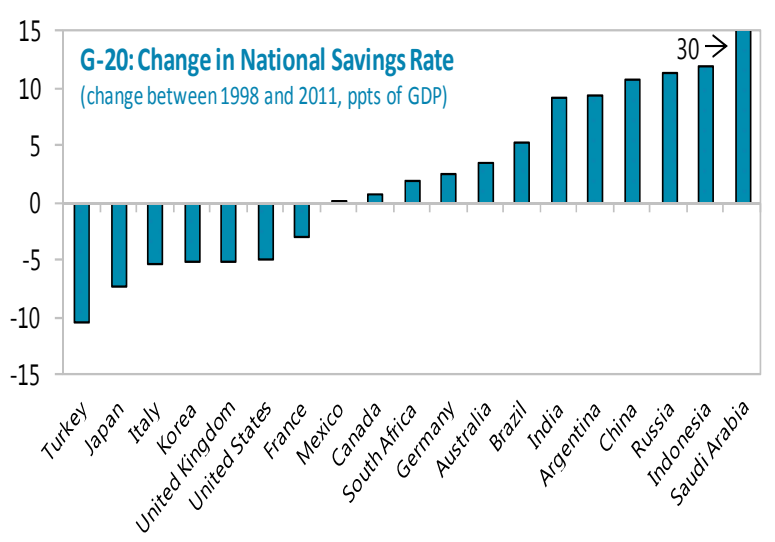

Source: WEO, and IMF staff calculations.

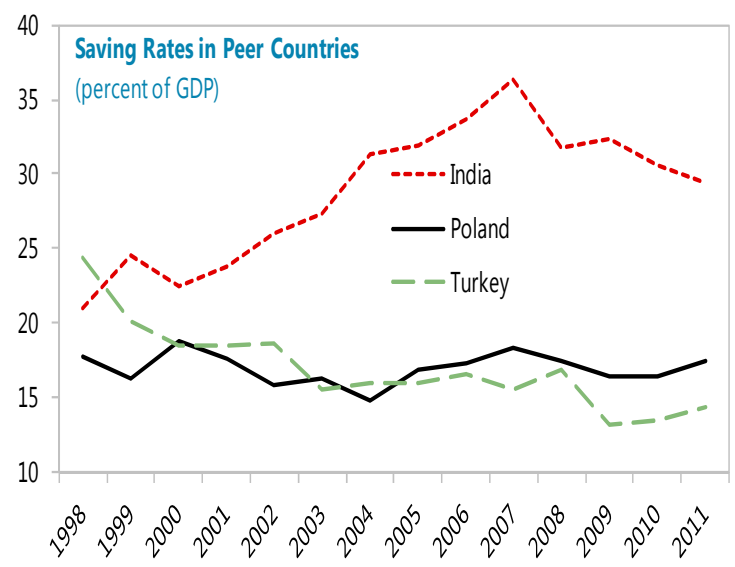

Source: WEO; and IMF staff calculations.

3. The decline in Turkish savings has been concentrated in the private sector...Since the late 1990 's, a decline in private savings of 15 percentage points of GDP has more than accounted for the decline in total savings. Moreover, unlike aggregate savings which have been roughly flat since 2003, private savings have declined almost continuously since the 2001 crisis and subsequent recovery, with a close to 5 percentage points of GDP decline in the last three years alone.

\section{4. ....and mostly among households} rather than corporates. There are no

national accounts estimates of household and corporate savings, which are then measured on the basis of household and corporate surveys (the latter might be less statistically representative than the former, as they often exclude a significant portion of SMEs). Moreover, these measures tend to express savings as percent of household disposable income or as percent of corporate sales, and these are not directly mappable to GDP.

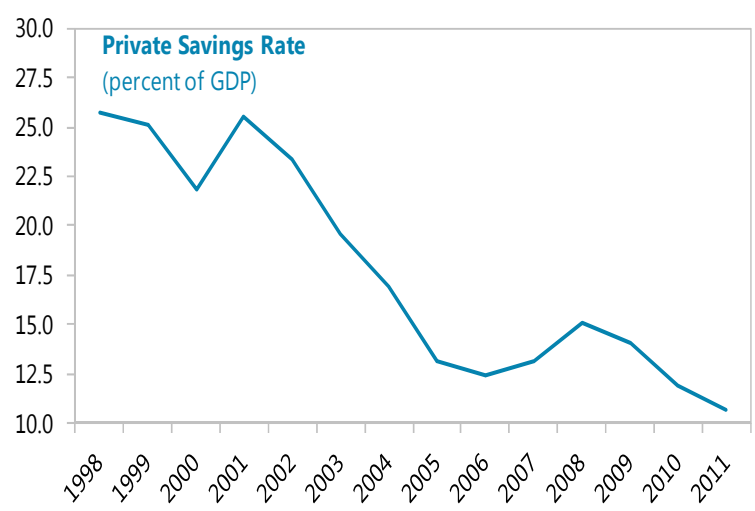

Source: Ministry of Development



Still, as the World Bank (2012) makes clear, available evidence suggests that corporate profitability in Turkey recovered after the 2001 crisis and is now comparable to late 1990's levels. On the other hand, both mean and median household savings did decline over the last 
decade, though interestingly the decline was much less pronounced if one includes purchases of durables as part of savings. ${ }^{2}$

\section{Why did private savings fall?}

\section{The literature has found a consistent set of indicators that explains the decline in} savings. Several studies including inter alia IMF (2007), van Rijckeghem (2010), World Bank (2012), Matur et al. (2012) have looked econometrically at the savings decline and have converged to a consistent set of explanatory variables, which relate directly to the radical transformation of the Turkish economy following the successful stabilization in the early 2000s. More specifically, these studies found that savings declined for the following main reasons: ${ }^{3}$

- $\quad$ higher public savings: over the last ten years, public and private savings have been almost perfect mirror images of each other, with the 8 percent of GDP cumulative increase in public savings offset by the decline in private savings. ${ }^{4}$ Not surprisingly, the offset between the two has been stronger than in other peer countries. This, however, should

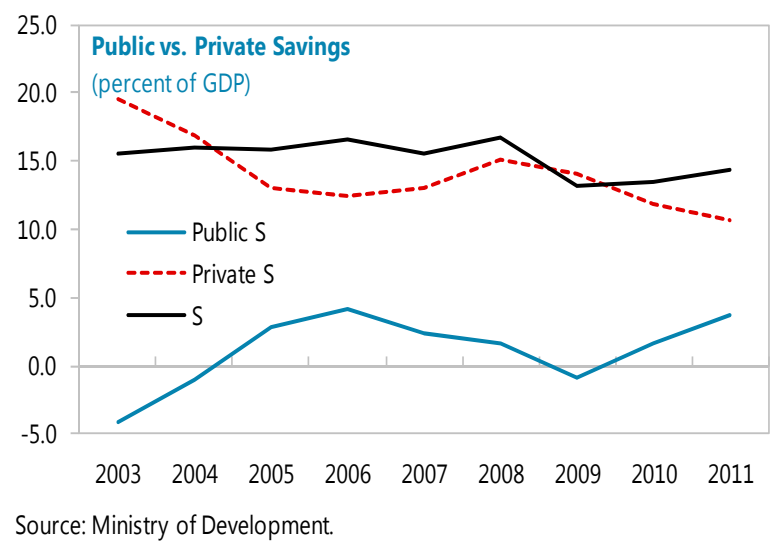
not be seen as unambiguous evidence of Ricardian equivalence, as the link between public and private savings could have been indirect and episode-specific (credible fiscal consolidation in the early 2000's created macro-financial conditions that led to lower savings - see below), rather than reflecting economic agents piercing the veil of intertemporal public finances. In addition, exogenous factors may have simultaneously affected public and private savings in opposite directions. ${ }^{5}$ At any

\footnotetext{
${ }^{2}$ In other words, the decline in the standard definition of savings stemmed in part from rapid increases in durables consumption which outpaced overall consumption.

${ }^{3}$ The exact quantitatite contribution of each factor to the decline in savings varies from study to study, because of differing sample periods, methods, etc.

${ }^{4}$ The offset is not so clear-cut before 2003, but high inflation in the 1990s and early 2000's complicates the proper disaggregation between public and private savings (as inflation is implicitly a tax on private savings that benefits the government). While measures of inflation-adjusted public/private savings exist, they are imperfect at best.

${ }^{5}$ Post-2009, the global recovery and normalization of financial conditions are behind the recovery and resumption of credit in the Turkish economy, contributing to higher public savings and lower private savings.
} 
rate, econometric estimates of the Ricardian offset for Turkey that control for other variables lie between 0.4 and 0.8 , high but not unity. ${ }^{6}$

- $\quad$ greater macroeconomic stability: with greater economic stability (proxied by the inflation rate, which has fallen sharply over the last decade), households felt less need for precautionary savings. Political stability, not captured in the studies, has certaintly been an important part of the mix as well.

- $\quad$ greater access to credit: the stabilization of the Turkish banking system opened the door for credit to expand ${ }^{7}$, softening households and corporates' liquidity constraints, again reducing the need for precautionary savings, and allowing agents to better smooth consumption over time.

- $\quad$ finally, lower real interest rates, expanded coverage of the social security system, and demographic factors played some role in the savings decline. ${ }^{8}$

6. At the same time, it is important from a diagnostic and policy perspective to recognize those reasons that could have but did not contribute to the decline in savings. In Turkey, savings did not decline because of changes to the tax system that might have disincentivized them; in fact, the country relies proportionately little on income taxes, while consumption taxes represent a very large share of tax revenues. Similarly, while there is always room to improve the functioning of financial markets and expand the range of financial instruments for savings, there is no financial repression to speak of that could be distorting savings decisions.

\section{Why do low savings matter?}

7. Low savings are a key reason behind the country's economic booms and busts. Historically, Turkey's investment rate has averaged around 20 percent of GDP, in line with

\footnotetext{
${ }^{6}$ Lack of full Ricardian equivalence makes sense in Turkey, given the large number of liquidity constrained households among other things.

${ }^{7}$ Since 2005 , credit as a share of GDP has increased by some 30 percentage points. Needless to say, this should not mean that more credit is always a good thing.

${ }^{8}$ One should mention here important factors that boosted savings during this period. Chief among these was higher growth in income per capita, consistent with evidence from other regions (see Carroll and Weil, 1994) that, in growth accelerating episodes, higher growth precedes and statistically causes higher savings, and not the other way around. Also, note that Matur et al. (2012) included both the level of income and its growth and found a positive effect on savings from the former but a negative effect from the latter.
} 
rates in many comparable countries. This is significantly higher than the savings rate, which has been at or below 15 percent of GDP for much of the last decade. In other words, the economy as a whole is "credit constrained" so that when capital inflows are ample, investment expands rapidly and the current account deteriorates ${ }^{9}$; in reverse, when external financing becomes scarce, investment and the current account deficit have to retract rapidly. The resulting investment booms and busts, directly tied to the capital flows cycle, are the key driver of output volatility in Turkey, with the implication that raising savings would be a good way to tame this volatility. It is worth noting that investment volatility is significantly higher in Turkey than in many peer countries with similar average investment rates but, not surprisingly, higher savings.

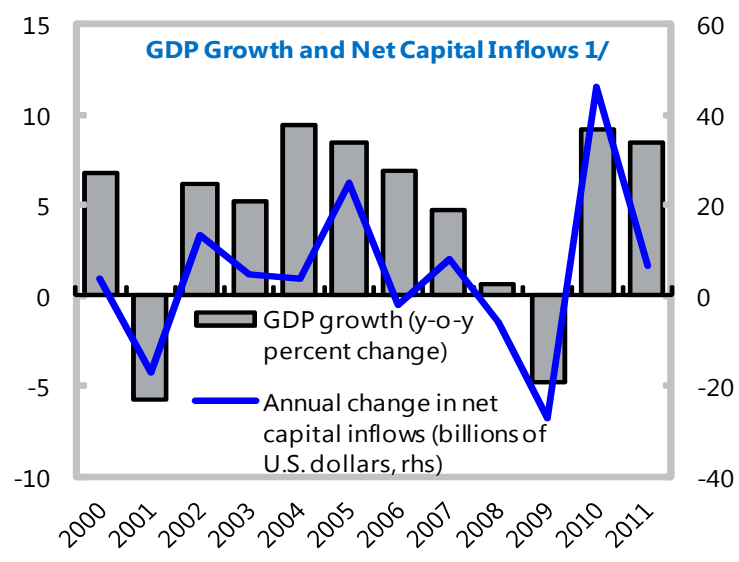

Sources: Central Bank of Turkey; and IMF staff calculations.

1/Includes errors and omissions.

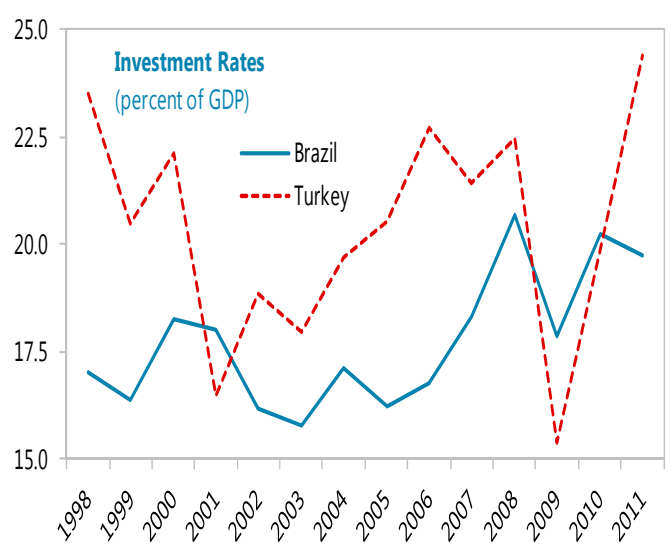

Source: WEO

\section{Beyond output volatility, higher savings will be needed to realize Turkey's}

medium-term potential. Fully tapping into the opportunities offered by the country's young population, strategic location, and very low female labor force participation could require higher investment rates than at present. Some like Rodrik (2012) have even suggested a "target" investment rate of 28 percent of GDP, about 3-4 percentage points higher than the already high (by Turkish standards) 2011 rate. There is simply no way that this target can be sustained given current savings rates, for it would imply running annual external deficits in excess of 12 percent of GDP. Higher savings could thus help Turkey achieve not only less volatile growth but higher growth as well.

\footnotetext{
${ }^{9}$ Strong consumption (including of durables) contributed to the large deterioration in private savings over the last three years, and in this sense it contributed to the widening of the current account deficit as much as investment did. However, higher public savings compensated for the decline in private savings over this period, so viewed from an S-I perspective the rise in investment fully explains the deterioration in the current account.
} 


\section{B. Policy Options}

\section{The laissez faire approach}

9. It would be tempting to believe that savings will increase on their own, with no need for policy action. There are three arguments in support of this view. The first is that the sustained gains in terms of stability and policy credibility of the last ten years have created the conditions for durable growth, and that savings will increase as a result of this. After all, many countries that experienced growth take-offs also saw subsequent increases in their saving rates. ${ }^{10}$ The other argument is that the sharp increase in durables consumption in recent years, the result of higher incomes, improved confidence in the future, and greater availability of credit, will taper off soon once pent-up demand for these goods is satisfied.

10. Such complacency would be misguided however. It is not a given that the jump in durables consumption was a "one time thing," as pent up demand can take many years to be satisfied and can ratchet up to higher-end goods as incomes rise. Similarly, savings need not automatically increase as incomes grow, and in fact they did not in the last decade when growth was very high in Turkey. It would also be prudent not to count on demographic trends to boost savings in the future: in Turkey, the projected decline in the youth dependency ratio (good for savings) will be accompanied by an increase in the old-age dependency ratio (bad for savings), so that the net result could be zero or only slightly positive (Van Rijckeghem, 2010).

\section{So what can be done?}

The government should be commended for reforming the voluntary private pension system. With private pension assets accounting for less than 2 percent of GDP, there is significant room for growth if the system can be made more attractive. ${ }^{11}$ The government recently replaced existing tax advantages with matching government contributions. This reform has tilted the incentives toward those with lower incomes and savings, and at the same time it has expanded coverage by including the many who do not pay taxes. In line with World Bank recommendations, the government also lengthened the vesting period and imposed penalties regarding the vesting of state matching contributions for early

\footnotetext{
${ }^{10}$ This is, again, the Carroll and Weil (1994) view of the world. Note that these authors rationalized the increase in savings during episodes of rapid income growth with the existence of habits in consumption.

${ }^{11}$ Private pension accounts have not been very popular in Turkey.
} 
withdrawals, to keep people in the system. It is too early to tell whether the reform will be successful in generating new savings, ${ }^{12}$ but the changes go in the right direction.

11. However, more needs to be done, starting with higher public savings. Even if the underlying problem rests with too little private savings, this should not be taken to mean that the public sector has no role to play. After all, the structural primary fiscal balance, though significantly higher than ten years ago, remains some 2-3 percentage points of GDP below its pre-crisis levels. Bridging this gap would have two important benefits. First, with less than full Ricardian equivalence, it would help raise national savings, even if by a modest $1-1 \frac{1}{2}$ percentage points of GDP. Moreover, beyond this direct effect, there would be an indirect effect that could be quantitatively more important. A tighter fiscal policy would relieve pressure on monetary policy and, ceteris paribus, allow for a more depreciated real exchange rate. Of note, IMF (2007) found that REER overvaluation accounted for one fifth of the decline in private savings between 2001 and 2005, and staff believe the REER remains overvalued at present.

\section{In addition to a higher structural public balance, the public pension system} could be used to increase mandatory savings. This could be achieved, for example, by maintaining current contribution rates but reducing benefits. The difficulty of such a reform would be political, given that the last decade has already seen major changes to the pension system. Alternatively, the government could impose mandatory contributions to private pension accounts, but for this to succeed where similar plans failed in the past Turkey will need good oversight of the funds.

13. Finally, addressing informality and low female participation rate will be key, as these remain important obstacles to savings:

- $\quad$ Tackling informality, which accounts for some 40 percent of the labor force: efforts to address the large informal sector, which have yielded gains in recent years, need to be sustained. Informal workers earn some 15-20 percent less than their counterparts in the formal labor market after controlling for observed individual characteristics (Başkaya and Hülagü, 2011), while their probability of losing their income is much higher. Both these factors negatively affect savings. Even within the formal system, tighter compliance would contribute to savings given the high share of the population that declare earning the minimum wage for tax and pension contribution purposes, when their actual earnings are higher.

\footnotetext{
${ }^{12}$ Özel and Yalçın (2012) suggest that the reform might have only a modest impact, 1.5 percentage points of GDP at most.
} 
- $\quad$ Raising female participation in the labor market. At less than 30 percent, the female participation rate is very low by the standards of middle income countries. The ratio has been increasing in recent years however, and rapid gains over the last two decades in the educational attainment of women suggest this trend will continue.

\section{Concluding Remarks}

14. Raising national savings will require an ambitious, multi-pronged effort.

Furthermore, there is no guarantee that these efforts will succeed: it could be that the reform of private pensions will increase this particular form of savings but only at the expense of other forms; it could be that raising public pension contribution rates will push more people into informality, negating the gains. The fact that the national saving rate has been relatively stable over the last ten years despite large underlying changes in public and private savings should sound a note of caution. Still, the stakes are too important not to try: Turkey is a country with large potential, one that will remain partially unfulfilled for as long as its saving rate remains low. 


\section{REFERENCES}

Başkaya, Y. S. and T. Hülagü, 2011, "Informal-Formal Worker Wage Gap in Turkey: Evidence From A Semi-Parametric Approach," Central Bank of the Republic of Turkey Working Paper 11/15.

Carroll, C. D. and D. N. Weil, 1994, "Saving and Growth: A Reinterpretation," CarnegieRochester Conference Series on Public Policy 40, pp. 133-192.

IMF, 2007, "Safe to Save Less? Assessing the Recent Decline in Turkey's Private Saving Rate" IMF Country Report No. 07/364 (Washington: International Monetary Fund).

Matur, E. P., Sabuncu, A. and S. Bahçeci, 2012, "Determinants of Private Savings and Interaction Between Public and Private Savings in Turkey," Topics in Middle Eastern and North African Economies 14, pp. 102-125.

Özel, Ö. and C. Yalçın, 2012, "Private Pension Plans and Domestic Savings with Special Emphasis on the Turkish Case," Unpublished draft.

Rodrik, D., 2012, "The Turkish Economy after the Global Financial Crisis," Ekonomi-tek 1, pp. 41-61.

Van Rijckeghem, C., 2010, "Determinants of Private Saving in Turkey: An Update," Bogazici University Working Paper 2010/04.

World Bank, 2012, "Sustaining High Growth: The Role of Domestic Savings," Turkey Country Economic Memorandum, Report \#66301-TR (Washington: World Bank). 